Postharvest Biology and Technology, Volume 139, Issue May, 2018, pp. 135-149

DOI: $10.1016 /$ j.postharvbio.2017.11.019

\title{
Postharvest losses of fruit and vegetables during retail and in consumers' homes: quantifications, causes, and means of prevention
}

\author{
Ron Porat ${ }^{\mathrm{a}^{*}}$, Amnon Lichter ${ }^{\mathrm{a}}$, Leon A. Terry ${ }^{\mathrm{b}}$, Roger Harker ${ }^{\mathrm{c}}$, Jean Buzby ${ }^{\mathrm{d}}$
}

${ }^{\text {a }}$ Department of Postharvest Science of Fresh Produce, ARO, the Volcani Center, P.O. Box 15159, Rishon LeZion 7528809, Israel.

${ }^{\mathrm{b}}$ Plant Science Laboratory, Cranfield University, Bedfordshire MK43 0AL, UK.

${ }^{\mathrm{c}}$ Plant \& Food Research, Private Bag 92169, Auckland Mail Centre, Auckland 1142, New Zealand.

${ }^{\mathrm{d}}$ Economic Research Service, USDA, 1400 Independence Ave., SW, Mail Stop 1800, Washington, DC 20250-1800, USA.

*Corresponding author (R. Porat): phone +972-3-9683617; fax +972-3-9683622;

E-mail address: rporat@volcani.agri.gov.il 


\section{ABSTRACT}

The issue of food loss and waste (FLW) reduction has recently achieved much public attention as part of worldwide efforts to combat global hunger and improve food security. Studies conducted by various international and national organizations led by the FAO indicated that about one third of all food produced on the planet and about a half of all fruit and vegetables (F\&V) are lost and not consumed. FLW occurs during five key stages of the food supply chain: agricultural production, postharvest handling and storage, processing, distribution, and consumption. Large portions of FLW in developed countries occur during retail and consumption, and are largely related to logistic management operations and consumer behaviors. In light of the great importance of FLW reduction, the United Nations set up in September 2015 an ambitious goal to halve per capita global food waste by 2030 , and this decision was adapted by the US Federal Government, the EU Parliament, and many other countries. This first Adel Kader review article is dedicated to the subject of F\&V losses during retail and consumption, and contains the following chapters: 1) Introduction of the problem of global food losses; 2) Quantifications of F\&V losses during retail and consumption in the UK, US and other countries; 3) Causes and consumer decisions related to F\&V wastage; 4) Emerging new technologies for prevention of F\&V losses, including advances in logistics and cold chain management, retail packaging and technological innovations; 5) Other means to reduce F\&V losses, including consumer awareness campaigns, advertisement of home storage instructions and policy and legislative measures. Due to the great importance of reducing $F \& V$ losses, we encourage postharvest researchers to become more engaged with logistics and food supply-chain operations, and to conduct multidisciplinary research incorporating consumer behavior studies into postharvest research.

Keywords: Food loss; Fruit; Postharvest; Retail; Vegetables, Waste 


\section{Preface}

We are grateful for the honor of dedicating the first Adel Kader review article series to the subject of postharvest losses of fruit and vegetables (F\&V), of which Professor Adel Kader was one of the world's pioneers and leading researchers. Professor Kader truly realized and emphasized the great importance of quantification and prevention of postharvest food losses, in order to secure adequate food supplies and combat global hunger (Kader, 2005). Professor Kader also served as an expert contributor to the landmark publication "Global Food Losses and Food Waste" (FAO, 2011), which opened our minds to the significant global problem of food losses and waste along the supply chain.

\section{Introduction}

The increase in global population, together with the increased purchasing power of the burgeoning middle-class populations in developing countries with emerging markets will result in a projected increase in food demand of 50-70 \% by mid-century (Godfray et al, 2010; Parfitt et al., 2010; Bond et al., 2013). In contrast to this background of rising global demand, it is estimated that nearly one billion people are chronically under-nourished and suffer from nutritional deficiencies (Bond et al., 2013; UNEP, 2014). Furthermore, future food security - the ability of the world to provide enough safe and nutritious food for its entire population, is deeply threatened by emerging environmental constraints, such as stringent climate change, land degradation, and water scarcity (Wheeler and Von Braun, 2013; Liu, 2014).

The issue of food loss and waste (FLW) prevention has recently achieved high importance as part of worldwide efforts to combat global hunger and improve food security, as reducing food 
losses will increase food availability and security, and promote environmental sustainability (FAO, 2011; Shafiee-Jood and Cai, 2016). Accordingly, it was suggested that if the current rate of FLW were cut by half by 2050 , the world would need to produce about 1,314 trillion kilocalories (kcal) less food per year than it would in a "business-as-usual" global food requirements scenario. Thus, reducing FLW should be one of the leading global strategies for achieving sustainable food security (Lipinski et al., 2013). In light of the above-mentioned necessity to increase food availability, the Association of Public and Land-Grant Universities (APLU) has recently endorsed Universities in the United States, Canada, and Mexico to focus their future research on the key challenge of ensuring global food and nutrition security, including reduction of FLW (APLU, 2017). In addition, the UK Government has recently elevated "reducing waste" to one of the four key research priorities in its Agriculture and Food Security Strategy Framework (BBSRC, 2017). The global activities on FLW reduction are currently greatly inspired by the FAO's "SAVE FOOD: Global Initiative on Food Loss and Waste Reduction" program (FAO, 2015).

The term "FLW" refers to any decrease in edible food mass available for human consumption throughout the various segments of the supply chain (FAO, 2011; Okawa, 2015). Food losses occur during the early stages of the food supply chain including at production, postharvest storage, transportation, and processing, whereas food waste takes place towards the end of the food supply chain including retail and consumption (FAO, 2011, 2013) (Fig. 1). Food waste is largely related to improper behavior and decision making of suppliers, retailers, and consumers, which results in discarding of food that still contains adequate nutritional value and that could have been consumed (Parfitt et al., 2010; Lipinski et al., 2013; Okawa, 2015). 
FLW can also be divided into qualitative and quantitative losses. Qualitative losses refer to food losses due to poor perceived quality in terms of color, size, shape, flavor, etc., that result in low consumer acceptability, whereas quantitative losses refer to destructive losses due to physiological, mechanical, or pathological deterioration, or combinations of these (Kader, 2005). Worthy of notice is that a certain proportion of food waste is unavoidable, as it includes inedible parts and tissues, such as banana peels, apple cores, etc. (Ju et al., 2017).

Studies conducted by various international and national organizations, including the FAO, European Union (EU), Organization for Economic Co-operation and Development (OECD), the United States Department of Agriculture (USDA), the US and French Natural Resources Defense Councils (NRDC), the UK Waste Resource Action Program (WRAP), the Institution of Mechanical Engineers (IMechE), as well as many other governments, including Japan, China, India, various EU countries, etc., indicated that between 30 and $50 \%$ (1.2-2 billion tons) of all food produced on the planet is lost and not consumed (FAO, 2011, 2015; NRDC, 2012, 2015, 2017; WRAP, 2013; IMechE, 2013; Buzby et al., 2014; Okawa et al., 2015; FUSIONS, 2016). The estimated per-capita FLW levels peaks at 280-300 kg per capita per year in high-income European and North American countries and amounts 120-170 kg per capita per year in lowincome sub-Saharan African and South and Southeast Asian countries (HPLE, 2014).

Based on studies led by the FAO and other organizations, standard methodologies were developed for accurate measurement of FLW along five key stages (boundaries) of the food supply chain: agricultural production, postharvest handling and storage, processing, distribution, and consumption (FAO, 2011; Lipinski et al., 2013; UNEP, 2014; WRI, 2016). Food loss rates at each stage of the food supply chain are estimated by using the FAO's food balance sheets (FAO, 2011; WRI, 2016). Using FAO (2011) data, the NRDC (2012) report indicated that in 
North America (i.e., the US and Canada), Australia, and New Zealand, F\&V losses totaled: $20 \%$ during production; $3 \%$ during postharvest handling and storage; $1 \%$ during processing and packaging; $12 \%$ during distribution and retail marketing, and $28 \%$ at the consumer stage (Fig. 1). However, these data did not distinguish between fresh and processed forms of F\&V.

Studies indicated that in low-income countries food losses result largely from managerial and technical limitations in harvesting techniques, and storage, transportation, and processing activities, because of lack of proper cooling facilities, infrastructure, and packaging and marketing systems. In contrast, food waste in medium- and high-income countries relates mainly to consumer behavior and strict safety policies and quality standard requirements (FAO 2011, 2015).

Estimates of FLW vary among food categories, including F\&V, roots and tubers, cereals, oilseeds, milk, meat and fish, and sea food (FAO, 2011; Lipinski et al., 2013). According to FAO reports, the categories "F\&V" and "roots and tubers" account for 44 and $20 \%$ by weight, respectively, of the global total FLW, i.e., fruit and vegetables of all types together account for $66 \%$ by weight of total food losses (FAO, 2011; Lipinski et al., 2013). Furthermore, FAO reports indicate that between 45 and $55 \%$ of all $\mathrm{F} \& \mathrm{~V}$ produced worldwide are lost or wasted along the supply chain (FAO, 2011; Lipinski et al., 2013), and an NRDC report indicated that 52 $\%$ of all F\&V produced in the US, Canada, Australia, and New Zealand combined, are lost or wasted (NRDC, 2012).

According to the USDA, in the US alone F\&V losses in the retail and consumption stages are estimated at 18.4 and 25.2 billion pounds, (8.3 and 11.4 million tonnes) respectively (Buzby et al., 2014). More specifically, of the total amount of F\&V available for consumption at the retail and consumer levels in the US, $9 \%$ of fruit and $8 \%$ of vegetables are lost at the retail stage, and 
a further $19 \%$ of fruit and $22 \%$ of vegetables are not eaten at the consumption stage; i.e., in the US roughly $28 \%$ of fruit and $30 \%$ of vegetables are lost in these two stages (Buzby et al., 2014). A material flow analysis study conducted in Japan revealed that the single food category with the highest loss rate comprised vegetables (Ju et al., 2017). It should be remembered that fresh F\&V are living organic organisms and, as such, are very perishable food items with relatively short postharvest storage lives (Kader, 2002). Reduction of F\&V losses is of great importance, because these commodities are of great importance for human nutrition with respect to vitamins, minerals, phytonutrients, fibers, etc., that are essential for healthy human diets.

Notwithstanding the significance of food loss reduction for ensuring food security, it also has major environmental, economic, and sociological impacts. From the environmental point of view, FLW represent waste of precious natural resources used for food production; including land, fresh water, energy, and fertilizers. In addition, wasted food is commonly dumped in landfills, which results in excessive emission of methane, which is approximately 25 times more harmful to the ozone layer than $\mathrm{CO}_{2}$. Kummu et al. (2012) reported that $23-24 \%$ of total use of water, cropland and fertilizers are used to produce food that gets lost. According to FAO reports (2013), the blue-water footprint of food waste is about $250 \mathrm{~km}^{3}$, which is equivalent to the annual water discharge of the Volga River; and growing uneaten food occupies almost 1.4 billion hectares of land, which is nearly $30 \%$ of the world's agricultural land area. The carbon footprint of uneaten food is estimated to be equivalent to 3.3 Giga tonnes of $\mathrm{CO}_{2}(\mathrm{FAO}, 2013)$.

From the economic perspective, improving the efficiency of the food supply chain by reducing food losses, would reduce food costs to consumers and thereby increase food availability and reduce household expenditures (FAO, 2011). From the social aspect, reduction of FLW would assist in feeding the globe's $\sim 795$ million undernourished people, of whom 780 
million live in developing countries (IFPRI, 2016). Furthermore, about $12 \%$ of American and EU households are food insecure; therefore, "rescuing" safe and nutritious food that otherwise would have been wasted, and distributing it among poor populations, would greatly assist in fighting hunger and poverty - also in developed countries (Loopstra et al., 2015; IFPRI, 2016).

In order to reduce FLW, the United States Environmental Protection Agency (EPA) established the Food Recovery Hierarchy; an administrative pyramid that prioritizes actions organizations can take to prevent waste and redirect otherwise wasted food (Fig. 2) (EPA, 2016). Each tier of this pyramid focuses on different management strategies to reduce the amount of wasted food, or to use it. The first preferred option is simply to prevent waste by not creating it. Nonetheless, because there always will be a certain amount of food wasted, the EPA's pyramid proposes redistribution of any excess food to feed the poor and needy or, if that is not possible, to feed animals. Lower priority recommendations are to divert the organic food waste to industrial use, e.g., for biofuel production or composting; and the least preferred alternative covers dumping wasted food onto landfills.

In light of the great importance of FLW reduction for both food security and environmental sustainability, the 193 member states of the United Nations reached agreement in September 2015 on establishment of 17 new "Sustainable Development Goals" (SDG's) that aim to promote prosperity and well-being. Among these is the UN declaration of Goal 12.3, which aims "to halve per capita global food waste at the retail and consumer level, and reduce food losses along production and supply chains by 2030" (https://sustainabledevelopment.un.org/topics/sustainabledevelopmentgoals). This ambitious goal - to halve FLW by 2030 - was further approved by the US Federal Government, the EU 
Parliament, and many countries, and by the G20 Agriculture Ministers' meeting held in June 2016 in China.

The subject of global FLW has recently attracted much public attention, and many governments and international organizations are currently establishing policy regulations to deal with the problem. The main goal of the present review article is to provide a professional indepth analysis of the problem of postharvest loss and waste of F\&V during retail marketing and in consumers' homes, addressing in-depth quantifications, causes, and means of prevention. This review will focus particularly on postharvest losses of $\mathrm{F} \& \mathrm{~V}$, which are perishable horticultural produce with short shelf lives that, on a per weight basis, form the largest source of food products that go to waste.

\section{Quantification of $F \& V$ waste during marketing and consumption}

\subsection{Quantification of $F \& V$ waste during retail marketing}

The absolute amounts of food losses during retail marketing are relatively small as compared with those in the earlier production and later consumption stages of the food supply chain (FAO, 2011). Nonetheless, the issue of food waste in supermarkets recently gained much public attention for several reasons: (i) retailers are located towards the end of the supply chain, so that a large environmental impact already has been generated in production, transportation, packaging and other processing steps, before the food arrives at regional distribution centers and supermarkets; (ii) supermarkets concentrate large quantities of waste at a few physical locations, which offers possibilities of collecting the waste for other purposes; (iii) much of the food waste in supermarkets is clearly visible to the public and thus gains its attention; (iv) supermarkets are potentially good targets for investigation of food waste and subsequent implementation of 
appropriate measures for waste prevention; and (v) much of the food wasted in supermarkets is still suitable for human consumption, and thus could have been recovered and donated to charities to feed poor people (Cicatiello et al., 2016; Brancoli et al., 2017).

The exact amounts of FLW in general and of F\&V in particular, during retail marketing are not exactly clear. Buzby et al. (2014) estimated that retail-level losses for all food categories represent $10 \%$ of total FLW at the retail and consumer levels combined in the US, whereas other studies found much lower retail losses - between 1 and $5 \%$ (WRAP, 2011). Cicatiello et al. (2016) reported that a single supermarket occupying 5,300 $\mathrm{m}^{2}$ in a medium-sized town in Central Italy could have recovered as much as 23.5 tonnes of perfectly edible food, valued about $€ 46,000$ in one year. Brancoli et al. (2017) reported that F\&V accounted for $29 \%$ by mass of total food losses in Swedish supermarkets, corresponding to an annual loss of 6.4 tonnes per store. Another report indicated that $\mathrm{F} \& \mathrm{~V}$ accounted for $53 \%$ of the total monetary value of food losses in supermarkets in Austria (Lebersorger and Schneider, 2014). In the following paragraphs we provide critical up-to-date estimates of F\&V losses in supermarket chains in the UK, USA, and other countries.

\subsubsection{Quantification of $F \& V$ waste during retail marketing in the UK}

The issue of $F \& V$ waste was first articulated in modern times to the general public as a direct result of successful campaigns in 2007 by WRAP that was set up by the UK's Department of Environment and Rural Affairs in 2000. The 'Love Food, Hate Waste' campaign was primarily consumer focused, but along with the squeeze on household budgets that resulted from the global financial crisis in 2007-2008, it pressed supermarkets to react. The expansion of the Courtauld Commitment - now in phase three - since 2005 has enabled a forum for supermarkets and others 
to work collectively to reduce food and packaging waste. There is now continued interest from the British Government and, indeed, some mainstream supermarkets began to monitor, understand, and reduce food waste (WRAP, 2011, 2013; Bond et al., 2013; House of Lords, 2014; House of Commons, 2017). Examples of food waste campaigns include Sainsbury's Supermarkets' "Waste less, save more", Tesco Stores' "We have no time for waste" and Marks and Spencer's "Plan A". In 2013 Tesco were the first UK supermarket chain to start to openly publish data on food waste; they estimated that even though they served 50 million shoppers per week, less than $1 \%$ of food at Tesco was wasted, which however still equates 46,000 tonnes per year.

$\mathrm{F} \& \mathrm{~V}$ waste is an emotive subject, and the extent, accuracy, and resolution of available data on postharvest loss and waste are sometimes questionable, with the result that key waste-related performance indicators can be misreported. Most supermarkets in the UK are still not transparent regarding waste levels; calculation methodologies related to fresh produce losses and waste are commonly obscure and not peer-reviewed. In general, the quantification of food losses in the UK, and elsewhere, tends not to consider factors such as genotype, seasonality, implemented technologies, logistics and supply chain management, so that often data are inappropriately aggregated (Mena et al., 2014). This said, recently there perhaps has been too much emphasis on highlighting the extent of food waste rather than articulating the causal factors and proposing solutions to tackle it.

Terry et al. (WRAP, 2011) were commissioned by WRAP to evaluate the extent of F\&V losses and waste from farm gate to retail and wholesale. Eleven fresh produce types strawberry, raspberry, tomato, lettuce, apple, onion, potato, broccoli, citrus, avocado and banana - were selected, based on their consumption, postharvest physiology, and management. Eleven 
resource maps were created on the basis of: i) anonymized yet structured 1- to 2-h interviews with 45 UK fresh produce suppliers, wholesalers and retailers; ii) sampling of secondary waste data; and iii) tracking of specific fresh produce consignments. These maps showed the levels of loss and waste at each stage in the supply chain, alongside the main causes and technological recommendations for each product. Fig. 3 presents, for example, the resource map of potatoes, and Table 1 presents a summary of FLW percentages of all tested produce. The main causes of waste rarely were only generic but, nevertheless, the main recommendations from Terry et al. (WRAP, 2011) were as follows: (i) improve data on loss and waste; (ii) improve supply chain communications; (iii) review customer specifications; (iv) promote packaging optimization; (v) promote technology transfer and knowledge exchange; (vi) increase use of production planning systems. Overall, it was concluded that implementation of these recommendations could save $£ 400$ million to $£ 500$ million through commercial improvements.

\subsubsection{Quantification of $F \& V$ waste during retail marketing in the US}

A major difficulty in quantifying F\&V losses in the US is that the major national sources of data on FLW in the US do not break down data according to individual commodities or commodity groups. For example: the EPA estimates the total FLW mass entering municipal solid waste facilities (EPA, 2016); and the NRDC's reports on food waste (NRDC, 2012, 2017) are widely cited but predominantly are based on data from external studies, e.g., the FAO's (2011) report and ReFED (Rethink Food Waste through Economics and Data) program (2016). ReFED focuses on the costs and benefits of 27 food-waste prevention solutions, and their data for 2015 indicated that $13 \%$ of food waste in the US was generated in the "grocery and distribution" stage of the supply chain (NRDC, 2017). 
Another major source of US data is the USDA Economic Research Service's (USDA/ERS) set of food loss studies, which define food loss as the amount of edible food available for human consumption but not consumed, for any reason, e.g., cooking loss, spillage, breakage, and food waste. Also relevant to the present review are two USDA studies that provide underlying estimates of supermarket shrink rates for individual fresh F\&V (Buzby et al., 2009, 2016). Both studies estimated supermarket shrink percentages by subtracting total point-of-sale data from the corresponding total supplier shipment data for each fresh commodity, and both focused on supermarkets; neither included convenience stores, megastores, club stores, and "mom-and-pop" grocery stores. The sample of data used in the first study was obtained from over 600 stores in six large national and regional supermarket retailers (Buzby et al., 2009). The resulting 20052006 supermarket shrink data for fresh F\&V are currently used as a proxy for food loss in the USDA's Loss Adjusted Food Availability (LAFA) data series (USDA, 2017). The USDA used this data series to estimate that 4.4 billion pounds ( 2 million tonnes) accounting for $12 \%$ of fresh fruit and 5.2 billion pounds (2.4 million tonnes) accounting for $10 \%$ of fresh vegetables at the retail level go uneaten (Buzby et al., 2014). When each commodity was valued according to national average retail prices for 2010, using Nielsen Homescan data, the estimated values of this supermarket shrink were $\$ 4.2$ billion for uneaten fresh fruit and $\$ 6.9$ billion for uneaten fresh vegetables (Buzby et al., 2014).

The second USDA supermarket loss study provided supermarket shrink estimates for fresh F\&V during 2011 and 2012 (Buzby et al., 2016). The sample was larger than that used in the first study; it included one large national and four regional supermarket retailers for which Nielson's proprietary database provided data from roughly 2,900 stores in 45 states and the District of Columbia. The estimates obtained in this study are currently being reviewed by an 
expert panel for possible inclusion in LAFA (USDA, 2017). Figure 4 presents the estimated supermarket shrink rates for fresh fruit (in yellow) and fresh vegetables (in green), based on data from Buzby et al. (2016). Estimated shrink rates ranged from $2.2 \%$ for sweet corn to $62.9 \%$ for turnip greens. In general, leafy greens had the highest shrink rates for 2011-2012: turnip greens (62.9\%), escarole/endive (47.4\%), and collard greens (43.8\%). In the US, cooking greens have gained in popularity in light of the current juicing trends and the focus on healthy eating. According to Nielsen Perishables Group, retailers are increasing the amount of shelf space displaying cooking greens, and this can lead to higher shrinkage if the items are not handled optimally or sell more slowly than expected (Buzby et al., 2016).

\subsubsection{Quantification of $F \& V$ waste during retail marketing in other countries}

The amounts of $F \& V$ waste during retail marketing were evaluated in several other countries. In China, the amounts of F\&V waste during distribution were estimated to be around $10 \%$ (Liu, 2014). In South Africa, it was found that $F \& V$, together with roots and tubers, contributed $57 \%$ of the overall food waste, the majority of which (8.67 million tons per annum) was generated during marketing and designated as the "pre-consumer stage" (UNEP, 2014). Among European countries, overall retail food waste was estimated to be $4.2 \%$ in Austria, $5 \%$ in Germany, and $6.5 \%$ in Sweden (Lebersorger and Schneider, 2014). In Canada, retail losses were estimated at $11 \%$ (Gooch et al., 2010). In Israel, a questionnaire-based study was conducted by interviewing F\&V category managers of the country's three largest supermarket chains; whom were asked about retail waste rates of four major fruit crops - apple, citrus, banana and grape - and four major vegetable crops (tomato, cucumber, potato and pepper - which together form $\sim 70 \%$ of total F\&V marketing volume. Responses indicated that retail losses were between 4 and $17 \%$, 
depending on the product: relatively high retail losses of $15-17 \%$ were observed for banana, tomato, and cucumbers; moderate retail losses of $7-11 \%$ were observed for oranges, peppers, and grapes; and lower losses of 4-5\% were observed for potatoes and apples (Porat and Freidkin, unpublished data).

\subsection{Quantification of $F \& V$ waste in consumers' homes}

In developed countries the largest share of food losses along the supply chain occurs in consumers' homes or among other final users such as caterers and restaurants (Parfitt et al., 2010; Lipinski et al., 2013). For example, studies conducted by WRAP indicated that around $50 \%$ of total food loss across all sectors in the UK occurred as home waste (WRAP, 2013), and a report from the EU's Food Use for Social Innovation by Optimizing Waste Prevention Strategies (FUSIONS, 2016) indicated that household waste accounted for $53 \%$ of total food loss within the value chain in Europe. In the USA, an estimated $21 \%$ of the food supply at the retail and consumer levels went uneaten at the consumer level; this included consumption both at home and away from home, such as in full-service or take-out restaurants (Buzby et al., 2014).

Therefore, special attention should be focused on understanding the drivers of household food waste and on developing effective measures to ameliorate them (WRAP, 2008; Qi and Roe, 2016; Hebrok and Boks, 2017).

The exact proportions of F\&V among total household food waste are not perfectly known, but they certainly form a major component. According to the FAO (2011) F\&V account for 39 $\%$ of household waste, and according to WRAP $40 \%$ (WRAP, 2008). More detailed studies conducted in 2012 by WRAP (2013) in the UK indicated that the total amount of wasted fresh vegetables and salads was nearly 1.6 million tons, of which approximately half (810,000 tons) 
was avoidable; and the total amount of wasted fresh and processed fruit in UK households was approximately 930,000 tons, of which approximately $40 \%$ (370,000 tons) was avoidable. In the UK the five fruit and vegetables that were most frequently thrown away whole and untouched, were apples -4.4 million per day, potatoes -5.1 million per day, bananas -1.6 million per day, tomatoes -2.8 million per day, and oranges -1.2 million per day (WRAP, 2008). In the following paragraphs we present critical up-to-date estimates of F\&V waste in consumers' homes in the UK, USA, and other countries.

\subsubsection{Quantification of $F \& V$ waste in consumers' homes in the UK}

Data on consumer-generated waste of F\&V in the UK ware first systematically collected in 2006 (WRAP, 2008). As described in Paragraph 2.1.1 for retail waste, the extent and accuracy of some of these reported data are questionable because the methodology used is either unclear, statistically flawed, and/or includes too many assumptions and extrapolations of data. Notwithstanding that most campaigns are conducted to rise attention to the problem of food waste, but no peer-reviewed reports are available that systematically have measured the extent and temporal flux of UK consumer-generated waste of fresh produce through the seasons or across years. Furthermore, this study concluded that some fresh produce types are more prone to waste than others but, although this is reasonable, the presented data are not normalized against consumption levels. For instance, banana and apple are reported by WRAP as being the main components of waste, but the Kantar data indicate that they are the most consumed fruit in the UK (WRAP, 2013).

\subsubsection{Quantification of F\&V waste in consumers' homes in the US}


In the USA, a USDA study by Muth et al. (2011) estimated consumer-level food loss by comparing estimates of total US household retail purchases (2004 Nielsen Homescan data) with total US at-home consumption for around 200 commodities (2003-2004 National Health and Nutrition Examination Survey; NHANES). Estimated consumer-level losses for fresh fruit ranged from $8 \%$ to $54 \%$; and estimated consumer-level losses for fresh vegetables ranged from $7 \%$ to $69 \%$. Based on the consumer-level loss estimates of Muth et al. (2011) in the USDA's LAFA data series (USDA, 2017), the USDA estimated that 9.5 billion pounds (4.3 million tonnes) accounting for $25 \%$ of fresh fruit and 12.8 billion pounds (5.8 million tonnes) accounting for $24 \%$ of fresh vegetables remained uneaten at the consumer level (Buzby et al., 2014). When each commodity was valued according to national average retail prices for 2010 by using Nielsen Homescan data, the estimated value of this supermarket shrink was \$10.4 billion for uneaten fresh fruit and $\$ 13.2$ billion for uneaten fresh vegetables (Buzby et al., 2014). The USDA and the RTI International institute (RTI) are currently conducting a study to update the consumer-level loss estimates for each commodity in LAFA (Muth et al., 2017).

\subsubsection{Quantification of $F \& V$ waste in consumers' homes in other countries}

The amounts of F\&V waste in consumers' homes in several other countries also were evaluated. For example, a detailed study of food waste habits in Danish households revealed that the most wasted food categories were fresh vegetables (30\%), followed by fresh fruit $(17 \%)$, bakery products (13\%), drinks, confectionery and desserts (12\%), meat and fish (7\%), dairy and eggs (5\%), etc. Nonetheless, about half of the F\&V waste was unavoidable; it included peels, cores and seeds (Edjabou et al., 2016). Overall, vegetable food waste contributed $145 \mathrm{~kg}$ 
to the annual total amount of $434 \mathrm{~kg}$ of residual household waste in Denmark (Edjabou et al., 2016).

In Israel, a one-week waste-analysis survey was applied to 192 middle-class households, comprising 632 persons; the survey included evaluation of 2,544 $\mathrm{kg}$ of waste, of which $45 \%$ $(1,139 \mathrm{~kg})$ was organic food waste. Moreover, it was found that about half $(54 \%)$ of the total amount of food waste was avoidable, and $67 \%$ of the avoidable wastes comprised F\&V; this means $0.45 \mathrm{~kg}$ of F\&V waste per family per day (Elimelech and Ayalon, manuscript in preparation). In Canada, the total amount of food losses along the supply chain were valued at \$27 billion, about half of which (51\%) was believed to occur in consumers' homes (Gooch et al., 2010). However, the relative proportion of the total amount of waste formed by F\&V was not reported.

\section{Causes of $F \& V$ waste during retail and consumption}

To achieve the ambitious objective of halving food waste by 2030 , as declared in UN SDG12.3, will require detailed understanding of the drivers and reasons for food waste generation along the food supply chain, and identification of "hot spots" of waste (Priefer et al., 2016). Furthermore, because much of food waste is attributable to consumers, it is especially critical to understand consumer awareness, perceptions, opinions, and attitudes that could partly explain the high level of household food waste (Qi and Roe, 2016). The main reason for retail and consumer waste of $\mathrm{F} \& \mathrm{~V}$ is that they are perishable fresh organic produce with relatively short shelf lives as compared with dry produce; therefore they require proper cooling, handling, planning, and ordering (Kader, 2002; Eriksson et al 2016). In general, the main causes of F\&V losses during retail marketing are related to inadequate cold storage and maintenance of the cold 
chain, and over-stocking because of inaccurate demand forecasts and ordering (Nunes et al., 2009; WRAP, 2011; Eriksson et al 2016; Priefer et al, 2016). In contrast, the main causes of consumers' waste are related to lack of planning, over-purchasing, poor home-storage management, etc. (WRAP, 2013; Priefer et al., 2016). Understanding consumer food waste is a very complex issue that involves both socio-cultural and material factors, including lifestyle, gender, age, household size and income, presence of children, planning meals, use of leftovers, home storage facilities, organization of the refrigerator, among others (HPLE, 2014; Qi and Roe, 2016; Hebrok and Boks, 2017). In the following paragraphs, we present detailed analyses of the main causes of F\&V waste by consumers' and the influences of human behaviors, and attitudes and decision makings considerations regarding food waste.

\subsection{Causes of F\&V losses in consumer's homes}

There is an increasing literature on the role of consumer behavior in explaining food waste, which is reflective of recent concerns over such waste in many Western countries (e.g. Stefan et al., 2013; Parizeau et al. 2015; Stancu et al., 2016; Thyberg and Tonjes, 2016), but there is a paucity of similar studies in Asia or developing countries. The literature tends to consider all food waste at a collective level, rather than specific categories such as 'fresh fruit' and 'fresh vegetables and salads', even though these combined categories comprise $20 \%$ to $70 \%$ of all wasted food (Parfitt et al., 2010). In this section, we consider the literature on food waste and identify product-related issues and consumer attitudes that contribute to households' disposal of fresh F\&V.

\subsubsection{Consumers' behavior and food waste}


The theory of planned action hypothesizes that consumers' intentions to perform a behavior can be predicted according to their attitudes towards the behavior, the perceived social pressure to undertake that behavior (i.e. subjective norms) and their perceptions that the behavior is under their own control (perceived behavioral control, PBC; Ajzen 1991). Stancu et al. (2016) created such a structural model for over 1,000 Danish consumers in which it was found that shopping routines, leftover routines and PBC were more important than intentions in explaining food waste and, in doing so, confirmed similar results obtained for Romanian consumers (Stefan et al., 2013). From an applied perspective this establishes that consumers' attitudes regarding foodwasting behavior including the extent that it is negative, worrying, foolish, and harmful to the environment have a lesser impact on food waste than having developed good food-provisioning routines and habits. $\mathrm{PBC}$, in these studies, reflects the extent that consumers' perceive they have control or are powerless to control their food waste (e.g. through their own behavior and habits). For these reasons, Section 3.1 focusses on: (i) over-provisioning and purchasing of food, (ii) failure to consume, including no strategies to use leftover F\&V in baking and juicing and (iii) ability to manage inventory and quality within the home.

\subsubsection{The Food Environment}

Consumers' access to safe, healthy, reliable and trusted supplies of food is an important aspect of the food environment (e.g. Morland et al., 2002; Gao et al., 2012). Trends suggest that domestic food waste is a greater issue in affluent urban communities supported by global supply chains (Parfitt et al., 2010; Thyberg and Tonjes, 2016). For these affluent consumers, F\&V that were once available on a seasonal basis are now available all year (Thyberg and Tonjes, 2016). 
Virtually all households have at least one refrigerator (Parizeau et al., 2015; Waitt and Phillips, 2016), but the question is whether or not consumers decide to store F\&V this way. In a UK survey, only $2-3 \%$ of consumers thought it was important to store $\mathrm{F} \& \mathrm{~V}$ in refrigerators (WRAP, 2008). Given that temperature is the single most important factor governing the maintenance of F\&V quality (Wills et al., 1998), holding F\&V at ambient temperatures in the home is likely to contribute to rapid deterioration.

For those consumers who chose to store their $\mathrm{F} \& \mathrm{~V}$ in refrigerators, the way they manage the food inventory within the refrigerator can result in waste, particularly when food gets forgotten and/or becomes (or is perceived to become) contaminated by touching other items (Waitt and Phillips, 2016). Worry over food poisoning is a primary reason that US consumers discard food (Neff et al., 2015). Routines around the 'ridding refrigerators of old produce' are perhaps most critical to the disposal of food. Some consumers undertake 'ridding' regularly; throwing out what they think is past its best or will not provide the desired sensory experience, while other consumers do this on an ad-hoc basis as they are reminded by the need for a particular ingredient for a meal (Waitt and Phillips, 2016). It is these routines of disposal rather than the specifications of domestic refrigerators that are likely to be the larger contributor to F\&V waste.

\subsubsection{Shopping}

Food provisioning is a continuous and cyclic process including the acquisition, preparation, cooking, eating and disposal of food (Marshall, 1995). Society expects food decision-makers, who are often under severe time pressures, to make good food choices for themselves, their family and friends (Bava et al., 2008; Evans 2011). Social marketing campaigns provide constant reminders that people should eat F\&V (Havas et al., 1995; Pollard et al., 2008) and 
consumers are well aware of the importance of F\&V in their diet and select it on the basis of its contribution to family health (Jaeger and MacFie, 2001). For some consumers, ready access to fruit in the home is a source of affirmation and prestige or, if fruit is not available, embarrassment (Campbell et al., 2009). Pressures to be good providers contribute to the probability that consumers will be biased to purchase $\mathrm{F} \& \mathrm{~V}$, but later fail to eat it. This is a common phenomenon as it is well known that good intentions are poor predictors of compliance (Bowman et al., 2004).

There are three ways that many consumers manage inventory in the home: (1) shopping once a week with supplementary shops allowing replenishment of perishable $F \& V$, (2) shopping once a week and purchasing a range of fruits that ripen at different times to ensure both quality and availability throughout the week and (3) shopping once a week with the recognition that fruit inventory will run out before the next replenishment (Campbell et al, 2009). Recent in-home interviews and focus groups with high-income Chinese consumers in Tier 1, 2 and 3 cities indicate that accessing fresh $\mathrm{F} \& \mathrm{~V}$ is a priority, and this requires women to shop in the morning at local wet markets (often located within a few minutes of their apartments) for their provisions for the day (Harker, unpublished). A notable feature of the Chinese study, was that this daily morning provisioning activity took place even though all consumers had at least one refrigerator. It is likely that daily shopping is also a feature of other major high-density cities around the world and is reflective that shopping habits can rapidly change. Future changes to the way consumers shop include increased use of on-line shopping to purchase F\&V (White, 2016), and meal-kit delivery services that include F\&V (Bell, 2016).

The greater risk associated with consumers' shopping practices is that F\&V purchases may not relate to items that are needed at home. Richards (2000) in his analysis of AC Nielson 
HomeScan data noted variability in this disconnect between apple purchases and in-home inventory finding that consumers of Granny Smith apples were more responsive variations in household inventory than consumers of other apples. More recent surveys have found that about $70 \%$ of US consumers 'often' or 'always' check refrigerators and cupboards before shopping (Neff et al. 2015), but these values might be biased by consumers unwillingness to admit to poor shopping behavior. Generally, consumers become habituated in their shopping behavior based on expectations of a routine of standard meals, but the opportunity to prepare these meals can be disrupted in everyday life and result in the accumulation of un-used ingredients (Evans 2011; Waitt and Phillips, 2016). Some consumers suggest they are forced to purchase more than they need for a meal (e.g. whole cauliflower when only half is required; Evans 2011; Neff et al., 2015).

Over-provisioning might also occur during shopping when retailers encourage consumers to purchase more F\&V than they need. For example, grocery stores employ numerous promotional, price reductions, 'three for the price of one', eye-catching displays and other in-store marketing designed to trigger impulse purchase decisions (Bava et al., 2009). Yet many consumers resist these impulse purchases drawing on previous F\&V experiences; for example, mistrusting the good appearance of apples based on previous eating experiences or rejecting two-for-one offers because over-purchasing would lead to waste (Bava et al., 2009). Nevertheless, merchandising behavior, if unscrupulously used as a response to over-stocking or impending shrinkage from advanced deterioration, could simply pass on retail $\mathrm{F} \& \mathrm{~V}$ surpluses and quality risks into consumers' homes.

\subsubsection{Failure to consume}


Even for consumers who are thoughtful in their food purchases, unexpected changes to the meal routines may result in food not being used (Evans, 2011) or time pressures may force some ingredients to be dropped or swapped out (Bava et al., 2008). In these circumstances F\&V from the previous weekly shop may be displaced and discarded when new and 'fresher' items are purchased (Evans 2011). Consumers' often don't understand how to assess ripeness of fruit nor how to ripen fruit, and some fruits are forgotten if they take too long to ripen (Harker et al., 2007). Using data from an online survey asking consumers what fruit was in their homes and how long it had been there (Amos, 2005), three patterns of consumption were identified: (1) fruit are purchased and immediately consumers start to eat them such that inventory declines steadily, (2) fruit are purchased and left one or two days to ripen before consumers start to eat them and (3) fruit that have long shelf-lives are used as ingredients and garnishes, and so remain at low but constant levels over at least a two-week period (Fig. 5). There is little research on in-home management of inventory despite this having causality on waste.

Following purchase, the value that consumers' place on produce is likely to reduce according to the actual or perceived extent that it deteriorates while in their possession. Hypothetically, at the point in time an item is thrown away, its' perceived monetary value will be much lower than when it was purchased. This ongoing loss of the monetary investment in F\&V may be acceptable, if the amount thrown away is much smaller than the amount eaten and this over provisioning will ensure that the opportunity to eat healthy food is maintained within the home. For individuals, there may be an amount of $\mathrm{F} \& \mathrm{~V}$ that it is reasonable to waste on a weekly basis and this may differ significantly from societal pressures to have zero waste. However, there are few, if any, economic studies on this topic. 
As well as considering the monetary loss, it is important to consider if bias towards wasting $\mathrm{F} \& \mathrm{~V}$ is associated with sensory characteristics. Vegetables, even when cooked, are among the bitterest and hardest of any foods in human diets (Poelman et al., 2017). Bitterness has an impact on consumer preferences for foods with some variation in preferences based on human genetic and phenotypic sensitivity to bitter compounds (Shen et al., 2016). This sensory aversion to some vegetables is confirmed in lists of 'disliked foods' which feature vegetables including Brussels sprouts (Jaeger et al., 2017). Other F\&V, particularly fruit, represent a risk that an acceptable exterior appearance may hide internal defects (e.g. Gamble et al. 2010) and/or deliver bland and juiceless eating experiences (Harker et al., 1997).

There has been an increase in behavioral research on food addiction (Hebebrand et al., 2014; Singh, 2014). A recent project has ranked 35 foods according to the frequency with which consumers identified them as being addictive (Schulte et al., 2015). Highly processed foods such as chocolate, ice cream, pizza were the top three, while F\&V (broccoli, cucumber, carrots, banana and apple) were at the bottom (Schulte et al., 2015). By extension, we suggest that foods that are not addictive (e.g. most F\&V) are at risk of being wasted, while addictive foods are rarely wasted.

Leftovers after meals are often stored in the refrigerator for later consumption, a practice that invokes varying levels of concern over food safety among consumers (Waitt and Phillips, 2015). For F\&V, the concept of leftovers is akin to partially used fruit, vegetables and salads that have passed their best; e.g. a quarter of a bag of leftover spinach that a consumer might add to an omelette so that it is used (Evans, 2011). Campbell et al. (2009) found that the majority of consumers suggested alternative uses for fruit that had passed its best, including: baking, stewing and juicing. In a follow-up unpublished online survey, Campbell elicited the most likely and the 
least likely use of an apple with external blemishes and a moderately over-ripe banana (Amos, 2005). Disposing of this fruit was the least likely behavior for both the apple (32\% of consumers) and banana (42\%); rather consumers were most likely to eat the fruit (in spite of its poor appearance; $37 \%$ and $39 \%$, respectively) or use them in baking, stewing, freezing, or as an ingredient in something else (47\% and $54 \%$ ). This reinforces that knowledge, skills and recipes regarding the alternative ways to use $\mathrm{F} \& \mathrm{~V}$ that have deteriorated in the home have an important role in ensuring minimal waste of fresh produce.

\subsubsection{Quality in the home}

It should not be a surprise that consumers, lacking postharvest science knowledge, judge quality according to different criteria and that this sometimes lead to a misalignment between consumer perceptions and technical assessment of quality. Thus, consumers may dispose fruit that not only seem of reasonable quality according to postharvest assessments, but also which deliver an acceptable eating experience (Campbell et al., 2009).

F\&V rarely use expiry dates, except in prepared salads and fresh-cut products. Rather, the obvious cue to loss of freshness of food and F\&V is the time that it has been in the home (Parizeau et al., 2015). There has been surprisingly little research on perceptions of freshness, even though the topic has been central to a number of negative media stories (e.g. Anon 2016). Experimental auctions using fresh and stored apples have demonstrated that, while about $80 \%$ of participants are willing to make monetary bids based on their experience of the sensory quality of fruit, others are strongly influenced by knowing how long it has been stored: 'even though the old fruit tasted better, I think the new fruit would be better overall' (Lund et al., 2006). 
Along with time-in-the-home, consumers consider the deteriorating appearance of F\&V (discoloration, shrivel, wilting and development of rots) and tactile deformation that occurs during squeezing of fruit or bending of a carrot. It is rare, but not unknown, for consumers to comment that they smell or taste fruit before deciding that it should be thrown away (Campbell et al., 2009; Evans 2011). Consumers who were asked to taste fruit that they judged to be past its best (or close to being past its best) were often surprised by the good sensory quality of this fruit (Campbell et al., 2009). This misalignment between expectations of quality and willingness to discard fruit is supported by laboratory studies where consumers are given fruit of varying ripeness (as measured by puncture tests). Generally, such studies demonstrate that less ripe fruit attract lower hedonic scores than ripe fruit and much smaller, if any, hedonic consequence was associated with presentation of extremely soft fruit (e.g. Gamble et al., 2010; Hale et al., 2016). The caveat is that these extremely soft fruit are of good quality and softening is not reflecting the presence of incipient disorders such as low-temperature breakdown. Reductions in fruit waste may be achieved by resetting expectations of what is 'eating ripe'.

Consumers are willing to accept low levels of defects and deterioration in $\mathrm{F} \& \mathrm{~V}$, but once a threshold is passed they will discard a portion until the severity of the defect reaches the point that the entire product is thrown away (Campbell et al., 2009; Jaeger et al., submitted). There has been some research on the effect of defects, disorders and damage on consumer decisions to eat/not eat produce (Ares et al., 2008a), and more research on how these factors affect decisions to purchase/repurchase (Ares et al., 2008a; Gamble et al., 2010, Jaeger et al., 2016). Consumers' willingness to repurchase is influenced by both the severity and incidence of the defect (e.g. bruising in avocado) and this is attenuated by increases in price (Gamble et al., 2010). Research on lettuce found that consumers were more willing to accept visible deteriorations on whole 
leaves than leaves that had been minimally processed (Ares et al., 2008b). Eye-tracking studies have demonstrated that consumers quickly notice visual defects in apples and that once a defect is detected; consumers indicate they would not repurchase items (Jaeger et al., 2016). Decisions to consume at home are more lenient than decisions to purchase at a supermarket in regards to the presence of suboptimal foods and notably an 'apple with a spot' (small necrotic area along with a separate slightly damaged area that is symptomatic of a bruising) was treated more harshly than other foods (de Hooge et al., 2017). It is likely that defects that signal to consumers that there is potential food safety risk or likelihood of rapid future deterioration may be treated differently to defects that are merely cosmetic.

\subsubsection{Consumer behavior perspectives and needs}

F\&V should be considered as a special case when it comes to consumers' food-wasting behavior, because of the unique features associated with the storage and handling of biologically living plant organs and related fresh-cut products. However, this behavior should be considered in the broader context of increases in recommended daily requirements for $\mathrm{F} \& \mathrm{~V}$ consumption and the likely public health implications if these are not achieved. The focus should be on factors that improve compliance with dietary recommendations such that access to F\&V is improved in a way that ensures that more is eaten and less wasted. This needs to be founded on a good understanding of consumer behavior, but recognizing that it is notoriously difficult to change dietary behavior (Kapur et al., 2008). For this reason, postharvest technologists have an important role in developing biological and technical solutions that ensure consumer needs are met and barriers to consumption overcome. 


\section{Emerging technologies for prevention of $F \& V$ waste}

In addition to classical postharvest management operations, further reduction of $\mathrm{F} \& \mathrm{~V}$ losses will require development and implementation of novel postharvest technologies to maintain produce quality from the time it leaves the grower until consumption. In this section, we will describe new trends and promising emerging, innovative technologies that in the near future certainly will assist in reducing F\&V losses.

\subsection{Advances in logistics and cold chain management}

Keeping $\mathrm{F} \& \mathrm{~V}$ at their optimal storage temperature and maintaining the cold chain from harvest through sale has been and remains the core postharvest technology (Kader, 2003). However, in real-life situations, deviation from the optimal conditions is to be expected, therefore proper monitoring of storage and transportation conditions became an essential component of advanced logistics (Jedermann et al., 2014a). The resulting recorded temperature data can be further combined with large sets of initial variables that are under the responsibility of the primary producer; they include variety, yield, production area, season, preharvest treatments, produce-quality evaluations, etc. By gathering all these data, retailers are now able to switch from the traditional FIFO (first in first out) model to the more advanced FEFO (first expired first out) concept (Jedermann et al., 2014a). When using the FIFO model, all the retailer/distributer needed to know was when has the produce arrived? However, by adopting the more advanced FEFO model, the retailer/distributer needs to ask what was the initial quality of the produce on arrival? and what were the actual temperature conditions during storage and transportation? Accordingly, he must try to estimate the potential remaining postharvest storage life of the produce. Under the current traceability concept, the label posted on the crate by the 
grower contains only basic information, such as the grower's identification, country of origin, time of harvest, and produce variety and size. In the future, information technology (IT) means will enable use of cloud-based dynamic information on all preharvest and postharvest parameters of interest, and this will be incorporated into the virtual label and into a dynamic FEFO model.

Once shipments of F\&V leave the grower's site, real-time information on the location, temperature, humidity and any other relevant parameter, e.g., respiration, ethylene emission, will be collected. Technologies that enable by both growers and retailers to record, transmit and access data in real-time are based on radio-frequency identification (RFID), satellite communication, and cloud-based data accumulation, but some significant technological and economic challenges yet remain to be solved (Jedermann et al., 2014b; Zou et al., 2014). Deviations from the optimal conditions or expected arrival time will be incorporated into expected expiry time (EET) models.

Reefer containers, of which 2.1 million units (http://www.worldshipping.org/about-theindustry/containers/global-container-fleet) currently form the common and optimal distribution module for $\mathrm{F} \& \mathrm{~V}$, offer controlled solutions for transportation from the grower's location to the retail distribution center, while maintaining the optimal temperature for each type of F\&V. Better and improved design of temperature distribution within the containers will likely have a significant impact in prolonging the life span of $F \& V$, but the greatest impact will probably result from development of faster reefer vessels, establishment of direct transportation lines, and shorter turnaround times in the ports (Lee and Meng, 2014). Furthermore, advances in modified or controlled atmosphere (MA/CA) reefer containers - one of the leading maritime transportation companies reported it already has a fleet of 40,000 containers with MA/CA capacity - will add 
another dimension to protection against $\mathrm{F} \& \mathrm{~V}$ losses, especially for produce such as banana and avocado which markedly benefit from MA storage (Thompson, 2010).

Arrival of F\&V at the retail logistics center is the point at which the digital data obtained from the grower and the data collected along the journey can be matched against the actual appearance of the produce, and advanced monitoring systems - non-destructive or destructive sampling - will be used to adjust the correct EET and to formulate the distribution plans at the final retail sites. At the retail logistics center further post-transport treatments can be implemented along with repacking bulk produce into retail packages. Because multiple F\&Vs are channeled to common logistics centers from which they are further distributed to multiple final retail sites, significant compromises and deviation from the optimal temperature conditions are expected (depending on the consolidation level), and these forced changes in temperature management will vary in their cost in shelf life, depending on each type of F\&V. According to Hertog et al. (2014), it is computationally feasible to reduce waste in the retail logistics center and to find an optimal distribution solution for each product by applying combinatorial optimization modeling. Robotic order-picking systems are now able to handle orders and generate batches of $F \& V$ destined for the various end customers. Upon arrival at the retail shops, the time of arrival, the conditions at the display and the waiting time until sale will be incorporated into the EET of the F\&V, and these data will be visible to the consumers via smartphones or other digital display means. Further increases of the cool-shelf space volumes and improvements in stock management and of retail-packaging quality will likely improve the accuracy of the EET. 
It is well known that a large proportion of F\&V waste occurs in customers' homes, but so far the subject of "home logistics" has received very little attention. In the near future, we expect that the different conditions during transportation from the shop to the home will be integrated into updated EET models that will give consumers a better idea regarding how all these factors affect produce quality, and smartphone applications will alert the consumers to upcoming EETs. Furthermore, in parallel with the rising trend toward online shopping for $\mathrm{F} \& \mathrm{~V}$, control over this part of the supply chain is expected to improve. At present, there are two main storage conditions for $\mathrm{F} \& \mathrm{Vs}$ at home: relatively warm storage $\left(\sim 25^{\circ} \mathrm{C}\right)$ on the counter, and cold storage $\left(\sim 4{ }^{\circ} \mathrm{C}\right)$ in the refrigerator; however, introduction of a new intermediate temperature $\left(12-15^{\circ} \mathrm{C}\right)$ into commercial domestic refrigerators will likely provide great benefits by extending the shelf lives of various tropical and subtropical chilling-sensitive F\&Vs.

\subsection{Advances in retail packaging}

Packaging plays a vital role in protecting the food as it moves along the supply chain to the consumer, and in preventing food losses and waste (Verghese et al., 2015). "Retail package" generally refers to a ready-to-sell package of produce, such as: a packed bunch of bananas; a bag or tray of apples, lemons, or tomatoes; an individual shrink-packed zucchini, etc. (Fig. 6). The main advantages of marketing $F \& V$ in retail packages are: (i) the package provides protection from physical damage; (ii) the package maintains food safety, as it keeps the produce clean and protects it from dust, dirt, and contamination by microorganisms; (iii) the package facilitates display of printed information, including product identification and storage instructions; (iv) the package enables extension of the shelf life of the produce, by creating a high-humidity environment that reduces water loss and shrinkage; and (v) the package enables extension of the 
shelf life of the produce by creating a unique gas environment with low $\mathrm{O}_{2}$ and high $\mathrm{CO}_{2}$ concentrations that delay ripening and senescence processes (Verghese et al., 2015). Nevertheless, it is very important to design appropriate packaging systems for the various types of F\&V: the package unit must allow proper cooling and ventilation, and match the storage and transportation temperatures, as well as the respiratory behavior of the produce and its tolerances to low $\mathrm{O}_{2}$ and high $\mathrm{CO}_{2}$ environments (Kader et al., 1989). The beneficial effects of modified atmosphere packaging (MAP) in maintaining produce quality during transportation and retail marketing have been demonstrated for many types of $F \& V$, such as mangoes, strawberries and fresh-cut kale (Brecht et al., 2003). Packaging materials traditionally included various types of plastic boxes and films. However, in recent year's edible coatings and waxes, based on proteins, lipids, polysaccharides and their composites, are also regarded as types of packaging materials, because they also form a barrier between the food and its surrounding environment (Valdés et al., 2017).

The main advances and innovations in retail packaging are in the developments of new active and intelligent packages (Lee et al., 2015). Unlike a passive box or bag, an active package can dynamically absorb or release various compounds from or into the internal atmosphere of the packaging unit. Thus, development of active packages can assist in preserving produce quality and reducing waste by, for example, releasing safe antimicrobial agents to the surrounding environment or by absorbing oxygen, ethylene, excess moisture, off-odors, etc. (Mane, 2016). Also, intelligent packages can present information regarding product safety and quality by, for example: using RFID tags to track the product along the supply chain; using thermal sensors for food safety means; or using various ripening-indicator sensors that may indicate to the consumer when is the best time to eat the produce (Vanderroost et al., 2014). And finally, worth notice is 
that retail packs may contribute to reducing F\&V waste in consumers' homes by providing reclosable zip-lock or other re-sealable bags and pouches, which may retain optimum humidity, gas concentrations, and freshness also after the pack is opened at the consumer's home (Verghese et al., 2015). Marketing F\&V in varied package sizes also may assist in reducing food waste by enabling smaller households to purchase the amounts of produce they actually need.

\subsection{Technological innovations (apps and software)}

In addition to classical postharvest storage operations, many high-tech and food-tech innovations, including apps and electronic devices, were recently developed in order to prevent food waste and recover potentially rejected food. In fact, these technological innovations are actually changing the way food-sector operators and consumers interact nowadays with their food. At the retail level, use of Wasteless Ltd. RFID tags (https://wasteless.co/) now enables automatic and dynamic pricing of dairy, meat, and fresh-cut F\&V products according to their expiration dates, in order to promote sales of older products closer to these dates at reduced prices instead of throwing them away. Other apps, such as Tesco FareShare FoodCloud (http://www.fareshare.org.uk/fareshare-foodcloud/) in the UK, enable supermarkets to send alerts to partner charities in order to rescue surplus food that is still edible but is about to be dumped. Other apps, such as Winnow (http://www.winnowsolutions.com/), and LeanPath (http://www.leanpath.com/), provide food waste measurement tools in order to monitor food waste trends in commercial kitchens.

Several apps and electronic devices also were developed to tackle food waste at the household level. In this respect, worth notice is the commercialization of smart refrigerator devices and smart refrigerator cameras and apps, which track exactly what we have in our 
refrigerator at any time; they also monitor use-by dates and send out automatic top-up reminders to encourage people to eat what they already have - typically festering at the back of the fridge or in the salad box - by suggesting appropriate recipes. Many apps, such as FoodKeeper, developed by Cornell University, provide databases with cooking tips, food storage advice and information about expiration labels. These apps also may synchronize with our smartphones, and issue alerts when food expiration dates are near. Other interesting home storage devices are Bluapple (http://thebluapple.com/), which is a product that absorbs ethylene gas in home refrigerators, and RFID tags that detect ethanol accumulation in headspaces of food packages just before the product needs to be thrown away.

\section{Other means to reduce $F \& V$ waste}

\subsection{Consumer awareness campaigns}

Consumer surveys indicated that the majority of consumers are not conscious of the amounts of food they waste; nor of the environmental and financial costs of such waste. For example, an online survey $(n=1,010)$ of US consumer awareness revealed that three-quarters of respondents said they discarded less food than the average American (Neff et al., 2015), and interviews with 1,862 consumers in the UK revealed that only a few admitted that they wasted significant amounts of food (WRAP, 2007). Thus, it is necessary to continue to conduct public food-waste awareness campaigns in order to inform and educate consumers about waste generation. The best known and longest-running consumer awareness campaign is "LOVE FOOD HATE WASTE" initiated by WRAP in the UK in 2007. After five years, between 2007 and 2012, it was estimated that the campaign resulted in a reduction of 1.3 million tons in waste of household food and drink - from 8.3 million tonnes to 7.0 million tonnes - despite a $4 \%$ increase in the 
number of UK households (WRAP, 2013). However, verification of these extrapolated assumptions is problematic. One of the leading food loss reduction awareness campaigns, nowadays, is the "Think.Eat.Save" campaign, initiated in 2013 as a partnership between UNEP, FAO, and Messe Düsseldorf, in support of the UN Secretary-General's Zero Hunger Challenge (http://www.thinkeatsave.org/index.php/about). Other well-known global food loss reduction campaigns are: the Danish STOP WASTING FOOD (Stop Spild Af Ma), Norwegian FOR FOOD (ForMat), French ANTI FOOD WASTE (Antigaspi), Chinese EMPTY PLATE, Hong Kong's FOOD WISE, Japan's NO FOOD LOSS PROJECT, the German TOO GOOD FOR THE BIN, Australia's I LOVE LEFTOVERS, and the USA's I VALUE FOOD and SAVE THE FOOD campaigns. Of note is that ReFED - a collaboration among over 30 business, nonprofit, foundation, and government leaders - that was formed in 2015 in order to create a roadmap to reduce US food waste by $20 \%$, indicated that consumer campaigns (together with date labeling standardization and packaging adjustments), was one of the top three solutions with the greatest economic value for food waste prevention (ReFED, 2016).

\subsection{Publication of recommended storage instructions}

Large amounts of F\&V are lost in both the retail and wholesale stages and in consumers' homes because of improper storage management, therefore it is necessary to publish and advertise adequate professionally recommended storage instructions. At the retail level, some wholesale markets and/or supermarket logistics centers lack proper cooling infrastructures, or keep the produce at unfavorable temperatures; any such break in the cold chain obviously results in progressive shortening of produce shelf life (Kader, 2003). Furthermore, consumer research studies conducted by WRAP in the UK indicated that consumers are not always aware of how to 
store fresh produce correctly at home; a questionnaire-based study conducted in 2007 indicated that only $23-28 \%$ and $53-57 \%$ of consumers stored fruit and vegetables, respectively, in the refrigerator (WRAP, 2007). By comparing consumer storage behaviors with recommendations based on experimental research, it was estimated that in the UK at least 1.2 million tonnes of F\&V were being stored outside the refrigerator - food that would have benefited from being kept cool, and if even $5 \%$ of this produce had been eaten rather than thrown away there would have been 60,000 tonnes less waste (WRAP, 2008).

Any meaningful efforts to reduce $\mathrm{F} \& \mathrm{~V}$ waste should include presentation and advertising of recommended storage instructions. However, different types of $F \& V$ have differing storage requirements in term of optimal temperature and humidity, and this information should be provided to retail sector managers as well as to the general public. For example, bananas are very sensitive to chilling and should be stored at home outside the refrigerator; some fruit such as avocado and kiwi, should be allowed to ripen first on the counter and afterwards be placed in the refrigerator; most types of F\&V should be stored immediately in the home refrigerator; and root tuber vegetables, including potatoes, onions, yam and garlic, preferably should be stored in a dry, dark place at ambient temperatures.

Regarding the recommendation to provide storage instructions for retailers, wholesale market traders and supermarket logistic centers - the UC Davis Postharvest Technology Center (founded by Adel Kader) published a compatibility chart for short-term transport or storage of F\&V. It described three main groups of differing temperature requirements: Group 1 - recommended storage temperatures of $0-2{ }^{\circ} \mathrm{C}$ and relative humidity (RH) of $90-98 \%$ - optimal for temperate fruit and most leafy vegetables and berries; Group 2 - recommended storage temperatures of 7$10{ }^{\circ} \mathrm{C}$ and $\mathrm{RH}$ of $85-95 \%$ - optimal for citrus, subtropical fruits and many fruit-type vegetables; 
and Group 3 - recommended storage temperatures of $13-18^{\circ} \mathrm{C}$ and $\mathrm{RH}$ of $85-95 \%$ - optimal for root-type vegetables and most tropical fruits and melons

(http://postharvest.ucdavis.edu/Commodity_Resources/Storage_Recommendations/Compatibilit y_Chart_for_Short-term_Transport_or_Storage/).

Regarding the recommendations of storage instructions in consumers' homes - most public awareness campaigns include such recommended home storage instructions in order to inform consumers how and where to store their $\mathrm{F} \& \mathrm{~V}$; the main possibilities are in the refrigerator, on the counter, or in the pantry. In Israel, for example, researchers at the Dept. of Postharvest Science of Fresh Produce in the ARO, the Volcani Center, jointly prepared a pictogram of home storage instructions; it is published in the websites of both the Institute and the Ministry of Agriculture, and is presented to visitors and to the general public in the form of magnets that can be attached to the home refrigerator (Fig. 7). In the UK, WRAP conducted a study that tested the importance of refrigerated storage and wrapping with polyethylene film for maintaining quality and freshness of 17 types of F\&V during home storage; accordingly it published detailed recommendations for each produce (WRAP, 2008). In the USA, the USDA, the Department of Food Science at Cornell University, and the Food Marketing Institute (FMI) jointly publish "The Food Keeper", which provides consumers with useful guidelines for storing products (e.g., individual fresh F\&V) in the pantry, refrigerator, or freezer (FMI/Cornell/USDA, 2014).

\subsection{Policy and legislative measures}

In addition to soft measures, such as the public awareness campaigns and information platforms described in Paragraphs 5.1 and 5.2, governments and municipalities can adopt more rigorous approaches, such as imposing tax levies on generation of food waste. For example, in 
their landmark books, both Stuart (2009) and Bloom (2010) recommended that, at the first stage, governments introduce taxes on food waste and later entirely ban sending wasted food to landfills. Similarly, Priefer et al. (2016) recommended that EU countries impose taxes and fees on food waste, as a major economic instrument to fight food waste. In fact, 18 European member states already placed taxes on food waste sent to landfills, with a tax level on waste that exceeded 30 Euro per tonne, and in some EU countries waste-tax levels even reach 50-70 Euro per tonne - a financial burden that has stimulated factories, distributers, and supermarket chains to reduce their waste.

Other policy and legislative measures to reduce food waste include critical revisions of food safety regulations and marketing quality standards (Priefer et al., 2016). In addition, some countries, such as France, established additional new legislations on food waste, including a new law that, from 2016, banned supermarkets from throwing away edible excess food, mandated donations to charitable organizations, and adjustment of portion and packaging sizes, and promoted by law the use of "doggie bags" to collect leftovers from restaurants and food services (NRDC, 2015). In Japan, the Food Waste Recycling Law, established in 2001, compelled all business operators with more than 100 tonnes of food waste annually to regularly report the exact amounts of food waste, including that which was recycled as feed, fertilizers, etc.

\section{Conclusions and future perspectives}

The subject of FLW prevention recently gained much attention and priority among governments and international organizations, as a major means to achieve global food security and sustainability; this led to the very ambitious UN goal SDG12.3, which aims to halve global food losses by 2030 . However, proper implementation of this process will not be achievable 
without sufficient participation of postharvest researchers and technologists. In the present review we highlight the lack of coordinated postharvest research that addresses the interconnected networks of food supply chains "from farm to fork". In fact, the majority of postharvest research is currently conducted in isolation, without a full appreciation of the complex interactions and interdependent connections among postharvest biology and the influences of logistics and food supply-chain management systems.

Another important aspect highlighted in this review is the overwhelming importance of more active involvement of postharvest scientists in multidisciplinary teams that conduct research on food waste, and incorporation of scientific studies of consumer behavior into postharvest research. For example, it is necessary to understand how consumers interpret and understand produce quality evaluations, and what are their considerations in deciding to consume or throw away F\&V? Postharvest scientists must also focus more deeply on understanding the ripening and senescence processes that occur in consumers' home refrigerators, including evaluation of the effects of retail packaging options that influence consumers' interpretations of food safety and their resulting decision making that lead to in-home waste.

And finally, in the present review, we highlighted some innovative approaches, such as smart logistics managements, active and intelligent packaging, apps and software that are already becoming usable and that increasingly will be implemented in the near future; thus we encourage postharvest researchers to be involved in the development and implementation of these advanced technologies for retail and consumer use.

\section{Disclaimer}


The views expressed here are those of the authors and do not necessarily reflect those of the Economic Research Service (ERS) or the US Department of Agriculture (USDA).

\section{Acknowledgments}

The participation of R.P and A.L., of the ARO, the Volcani Center, was supported by research grant No. 430-0599-16 from the Chief Scientist of the Israel Ministry of Agriculture and Rural Development. This manuscript is contribution no. 730/17 from the Agricultural Research Organization, the Volcani Center, P.O. Box 6, Bet Dagan 50250, Israel. 


\section{References}

Ajzen, I., 1991. The theory of planned behaviour. Organiz. Behav. Human Decis. Proc. 50, 179211.

Amos, R.L., 2005. Factors influencing fresh fruit non-consumption in the home. Thesis submitted for Masters of Science in Food Science, University of Auckland, Auckland, New Zealand.

Anon, 2016. Half of supermarket apples are a year old: Foreign varieties eaten in Britain have been prevented from ripening while in transit. Daily Mail.

http://www.dailymail.co.uk/news/article-3692906/Half-supermarket-apples-year-oldForeign-varieties-eaten-Britain-prevented-ripening-transit.html\#ixzz4qRfYBaIc (accessed August 2017).

APLU, 2017. The challenge of change. Harnessing university discovery, engagement, and learning to achieve food and nutrition security. http://www.aplu.org/library/the-challenge-ofchange/File (accessed June 2017).

Ares, G., Gimenez, A., Gambaro, A., 2008a. Sensory shelf life estimation of minimally processed lettuce considering two stages of consumers' decision-making process. Appetite 50, 529-535.

Ares, G., Martınez, I., Lareo, C., Lema, P., 2008b. Failure criteria based on consumers' rejection to determine the sensory shelf life of minimally processed lettuce. Postharv. Biol. Technol. $49,255-259$.

Bava, J., de Hooge, I., Amani, P., Bech-Larsen, T., Oostindjer, M., 2015. Consumer-related food waste: causes and Potential for action. Sustainability, 7, 6457-6477.

Bava, C.M., Jaeger, S.R., Dawson, J., 2009. In-store influences on consumers' grocery purchasing decisions: a qualitative investigation. J. Customer Behav. 8, 221-236 .

Bava C.M., Jaeger, S.R., Park, J., 2008. Constraints upon food provisioning practices in 'busy' women's lives: Trade-offs which demand convenience. Appetite 50, 486-498.

Bava, C.M., Worch, T., Dawson, J., Marshall, D.E., Jaeger, S.R., 2012. Characteristics of eating occasions that contain fruit. Brit. Food J. 114, $1361-1379$. 
BBSRC, 2017. Research in agriculture and food security strategic framework. http://www.bbsrc.ac.uk/documents/agriculture-food-security-strategic-framework-pdf/ (Accessed August 2017).

Bell, K.K., 2016. The ultimate guide to the best meal kit delivery services. Forbes Media LLC. https://www.forbes.com/sites/katiebell/2016/03/21/the-ultimate-guide-to-the-best-meal-kitdelivery-services/\#77bf22da7375 (Accessed August 2017).

Bloom, J., 2010. American Wasteland. Da Capo Press, Cambridge, MA, USA.

Bond, M., Meacham, T., Bhunnoo, R., Benton, T.G., 2013. Food waste within global food systems. A Global Food Security report (www.foodsecurity.ac.uk) (accessed June 2017).

Bowman, D., Heilman, C.M., Seetharaman, P.B., 2004. Determinants of product-use compliance behavior. J. Marketing Res. 41, 324-338.

Brancoli, P., Rousta, K., Bolton, K., 2017. Life cycle assessment of supermarket food waste. Res. Conser. Recyc. 118, 39-46.

Brecht, J.K., Chau, K.V., Fonseca, S.C., Oliveira, F.A.R., Silva, F.M., Nunes, M.C.N., Bender, R.J., 2003. Maintaining optimal atmosphere conditions for fruits and vegetables throughout the postharvest handling chain. Postharv. Biol. Technol. 27, 87-101.

Buzby, J.C., Wells, H.F., Axtman, B., Mickey, J., 2009. Supermarket loss estimates for fresh fruit, vegetables, meat, poultry, and seafood and their use in the ERS loss-adjusted food availability data. U.S. Department of Agriculture, Economic Research Service, EIB-44. https://www.ers.usda.gov/publications/pub-details/?pubid=44103 (accessed August 2017).

Buzby, J.C., Wells, H.F., Hyman, J., 2014. The estimated amount, value, and calories of postharvest food losses at the retail and consumer levels in the United States, EIB-121, U.S. Department of Agriculture, Economic Research Service, https://www.ers.usda.gov/webdocs/publications/43833/43680 eib121.pdf?v=41817 (accessed June 2017).

Buzby, J.C., Bentley, J.T., Padera, B., Ammon, C., Campuzano, J., 2015. Estimated fresh produce shrink and food loss in U.S. supermarkets. Agriculture 5, 626-648.

Buzby, J.C., Padera, B., Bentley, J.T., Campuzano, J., Ammon, C., 2016. Updated supermarket shrink estimates for fresh foods and their use in ERS loss-adjusted food availability data. 
U.S. Department of Agriculture, Economic Research Service, EIB-155, 40 pp. https://www.ers.usda.gov/publications/pub-details/?pubid=44309 (accessed August 2017).

Campbell, R.L., Smith, B.G., Jaeger, S.R., Harker, F.R., 2009. Deterioration and disposal of fruit in the home: Consumer interviews and fruit quality. J. Sci. Food Agric. 89, 24-32.

Cicatiello, C., Franco, S., Pancino, B., Blasi, E., 2016. The value of food waste: An exploratory study on retailing. J. Retail. Cons. Ser. 30, 96-104.

de Hooge, I., Oostindjer, M., Aschemann-Witzel, J., Normann, A., 2017. Mueller Loose, S., Almli, V.L., 2017. This apple is too ugly for me! Consumer preferences for suboptimal food products in the supermarket and at home. Food Qual. Pref. 56: 80-92.

Edjabou, M.E., Petersen, C., Scheutz, C., Astrup, T.F., 2016. Food waste from Danish households: Generation and composition. Waste Manag. 52, 256-268.

EPA, 2016. Advancing sustainable materials management: 2014 fact sheet assessing trends in material generation, recycling, composting, combustion with energy recovery and landfilling in the United States. https://www.epa.gov/sites/production/files/201611/documents/2014_smmfactsheet 508.pdf(accessed August 2017).

Eriksson, M., Strid, I., Hansson, P.H., 2016. Food waste reduction in supermarkets - Net costs and benefits of reduced storage temperature. Resour. Conserv. Recyc. 107, 73-81.

Evans, D., 2011. Blaming the consumer - once again: the social and material contexts of everyday food waste practices in some English households. Crit. Public Health 21, 429-440.

FAO, 2011. Global food losses and waste. Extent, causes and prevention. http://www.fao.org/docrep/014/mb060e/mb060e00.pdf (accessed June 2017).

FAO, 2013. Food waste footprint. Impacts on natural resources. http://www.fao.org/docrep/018/i3347e/i3347e.pdf (accessed June 2017).

FAO, 2015. Global initiative on food loss and waste reduction. http://www.fao.org/3/ai4068e.pdf (accessed June 2017).

Food Marketing Institute (FMI), the Department of Food Science at Cornell University, and the U.S. Department of Agriculture, 2014. The food keeper. https://www.fmi.org/industrytopics/corporate-social-responsibility/food-keeper-food-storage-database (accessed August 2017). 
FUSIONS, 2016. Estimates of European food waste levels. https://www.eufusions.org/phocadownload/Publications/Estimates $\% 20 \mathrm{of} \% 20$ European $\% 20$ food $\% 20 \mathrm{waste} \%$ 20levels.pdf (accessed June 2017).

Gamble, J., Harker, F.R., Jaeger, S.R., White, A., Bava, C., Beresford. M., Stubbings, B., Wohlers, M., Hofman, P.J., Marques, R., Woolf, A., 2010. The impact of dry matter, ripeness and internal defects on consumer perceptions of avocado quality and intentions to purchase. Postharv. Biol. Technol. 57, 35-43.

Gao, H., Knight, J.G., Zhang, H., Mather, D., Tan, L.P., 2012. Consumer scapegoating during a systemic product-harm crisis. J. Market. Manag. 28, 1270-1290.

Godfray, H.C.J., Beddington, J.R., Crute, I.R., Haddad, L., Lawrence, D., Muir, J.F., Pretty, J., Robinson, S., Thomas, S.M., Toulmin, C., 2010. Food security: the challenge of feeding 9 billion people. Science 327, 812-818.

Gooch, M., Felfel, A., Marenick, N., 2010. Food waste in Canada. http://vcminternational.com/wp-content/uploads/2014/01/Food-Waste-in-Canada-November-2010.pdf (accessed September 2017).

Harker, F.R., Gunson, F.A., Jaeger, S.R., 2003. The case for fruit quality: an interpretive review of consumer attitudes, and preferences for apples. Postharv. Biol. Technol., 333-347.

Harker F.R., Jaeger, S.R., Lau, K., Rossiter, K., 2007. Consumer perceptions and preferences for kiwifruit: a review. Acta Hort.753, 81-88.

Harker, F.R., Redgwell R.J., Hallett, I.C., Murray S.H., 1997. Texture of fresh fruit. Hort. Rev. 20:121-224.

Havas, S., Heimendinger, J., Damron, D., Nicklas, T.A., Cowan, A., Beresford, S.A.A., Sorensen, G., Buller, D., Bishop, D., Baranowski, T., Reynolds, K., et al., 1995. 5 a day for better health - nine community research projects to increase fruit and vegetable consumption. Pub. Health Rep. 110, 68-79.

Hebebrand, J., Albayrak, O., Adan, R., Antel, J., Dieguez, C., de Jong, J., Leng G., Menzies, J., Mercer, J.G., Murphy, M., van der Plasse, G., Dickson, S.L., 2014. "Eating addiction”, rather than "food addiction", better captures addictive-like eating behaviour. Neurosci. Biobehav. Rev.47, 295-306. 
Hebrok, M., Boks, C., 2017. Household food waste: Drivers and potential intervention points for design e - An extensive review. J. Clean. Produc. 151, 380-392.

Hertog, M.L., Uysal, I., McCarthy, U., Verlinden, B.M., Nicolaï, B.M., 2014. Shelf life modelling for first-expired-first-out warehouse management. Phil. Trans. R. Soc. A, 372, 20130306.

House of Commons, 2017. Food waste in England. https://publications.parliament.uk/pa/cm201617/cmselect/cmenvfru/429/429.pdf (accessed September 2017).

House of Lords, 2014. Counting the cost of food waste: EU food waste prevention. https://www.parliament.uk/documents/lords-committees/eu-sub-com-d/food-wasteprevention/154.pdf (accessed September 2017).

HPLE, 2014. Food losses and waste in the context of sustainable food systems. A report by the High Level Panel of Experts on food security and nutrition of the Committee on World Food Security, Rome. http://www.fao.org/3/a-i3901e.pdf (accessed June 2017).

IFPRI, 2016. Global hunger index. The International Food Policy Research Institute report. http://www.ifpri.org/topic/global-hunger-index (accessed June 2017).

IMechE, 2013. Global food: waste not, want not. https://www.imeche.org/docs/defaultsource/default-document-library/global-food---waste-not-want-not.pdf?sfvrsn=0 (accessed June 2017).

Jaeger, S.R., Antúnez, L., Ares, G., Johnston, J.W., Hall, M., Harker, F.R., 2016. Consumers' visual attention to fruit defects and disorders: A case study with apple images. Postharv. Biol. Technol. 116, 36-44.

Jaeger, S.R., Bava, C.M., Worch, T., Dawson, J., Marshall, D.W., 2011. The food choice kaleidoscope: A framework for structured description of product, place and person as sources of variation in food choices. Appetite 56, 412-423.

Jaeger, S.R., Machín, L., Aschemann-Witzel, J., Antúnez, L., Harker, F.R., Ares, G., 2017. Buy, eat or discard? A case study with apples to explore fruit quality perception and food waste. (submitted). 
Jaeger, S.R, MacFie, H.J.H., 2001. The effect of advertising format and means-end information on consumer expectations for apples. Food Qual. Pref. 12 180-205.

Jedermann, R., Nicometo, M., Uysal, I., Lang, W., 2014a. Reducing food losses by intelligent food logistics. Phil. Trans. R. Soc. A 372, 20130302.

Jedermann, R., Pötsch, T., Lloyd, C., 2014b. Communication techniques and challenges for wireless food quality monitoring. Phil. Trans. R. Soc. A 372, 20130304.

Ju, M., Osako, M., Harashina, S., 2017. Food loss rate in food supply chain using material flow analysis. Waste Manag. 61, 443-454.

Kader, A.A., 2002. Postharvest biology and technology: an overview, in: Kader, A.A. (Ed.), Postharvest Technology of Horticultural Crops. Regents of the University of California, Division of Agricultural and Natural Resources, Oakland, CA. pp. 39-47.

Kader, A.A., 2003. Perspective on postharvest horticulture (1978-2003). HortScience 38, 1004 1008.

Kader, A.A., 2005. Increasing food availability by reducing postharvest losses of fresh produce. Acta Hort. 682, 2169-2175.

Kader, A.A., Zagory, D., Kerbel, E.L., 1989. Modified atmosphere packaging of fruit and vegetables. Crit. Rev. Food Sci. Nutr. 28, 1-30.

Kapur, K., Kapur, A., Ramachandran, S., Mohan, V., Aravind, S.R., Badgandi, M., Srishyla, M.V., 2008. Barriers to changing dietary behavior. J Assoc. Physic. India 56, 27-32.

Kummu, M., de Moel, H., Porkka, M., Siebert, S., Varis, O., Ward, P.J., 2012. Lost food, wasted resources: Global food supply chain losses and their impacts on freshwater, cropland, and fertiliser use. Sci. Total Environ. 438, 477-489.

Lebersorger, S., Schneider, F., 2014. Food loss rates at the food retail, influencing factors and reasons as a basis for waste prevention measures. Waste Manag. 34, 1911-1919.

Lee, C.Y., Meng, Q., 2014. Handbook of Ocean Container Transport Logistics: Making Global Supply Chains Effective. Inter. Ser. Oper. Res. Manag. Sci. 220.

Lee, S.Y., Lee, S.J., Choi, D.S., Hur, S.J., 2015. Current topics in active and intelligent food packaging for preservation of fresh foods. J. Sci. Food Agric. 95, 2799-8210.

Lipinski, B., Hanson, C., Lomax, J., Kitinoja, L., Waite, R., Searchinger, T., 2013. Reducing food loss and waste. Working Paper, Instalment 2 of Creating a Sustainable Food Future. 
World Resources Institute, Washington, DC.

http://pdf.wri.org/reducing_food loss_and_waste.pdf (accessed June 2017).

Liu, G., 2014. Food losses and food waste in China: a first estimate. OECD Food, Agriculture and Fisheries Papers, No. 66, OECD Publishing, Paris. http://dx.doi.org/10.1787/5jz5sq51731q-en (accessed June 2017).

Loopstra, R., Reeves, A., Stuckler, D., 2015. Rising food insecurity in Europe. The Lancet 385, 2041.

Lund, C.M., Jaeger, S.R., Amos, R.L., Brookfield, P., Harker, F.R., 2006. Tradeoffs between emotional and sensory perceptions of freshness influence the price consumers will pay for apples: Results from an experimental market. Postharv. Biol. Technol. 41, 172-180.

Mane, K.A., 2016. A review on active packaging: an innovation in food packaging. Inter. J. Envir. Agric. Biotech. 1, 544-549.

Marshall, D.W., 1995. Introduction: Food choice, the food consumer and food provisioning. In D. W. Marshall (Ed.), Food choice and the consumer (pp. 1-17). London: Blackie Academic \& Professional.

Mena, C., Terry, L.A., Williams, A. and Ellram, L. 2014. Causes of waste across multi-tier supply networks: Cases in the UK food sector. Int. J. Prod. Econ. 152, 144-158.

Morland, K., Wing, S., Roux, A.D., 2002. The contextual effect of the local food environment on residents' diets: The atherosclerosis risk in communities study. Amer.. J. Pub. Health 92, 1761-1767.

Muth, M.K., Karns, S.A., Nielsen, S.J., Buzby, J., Wells, H.F., 2011. Consumer-level food loss estimates and their use in the ERS loss-adjusted food availability data. Economic Research Service, U.S. Department of Agriculture, TB-1927, 123 pp.

Muth, M.K., Karns, S.A., Buzby, J., Kantor, L., 2017. Measuring food loss at the consumer level in the United States. Presented at the $15^{\text {th }}$ European Association of Agricultural Economists (EAAE) Congress 2017, Parma, Italy, August 28, 2017. https://www.ers.usda.gov/publications/pub-details/?pubid=47574 (accessed August 2017).

Neff, R.A., Spiker, M.L., Truant, P.L., 2015. Wasted food: U.S. consumers' reported awareness, attitudes, and behaviors. PLoS One 10, e0127881. 
NRDC, 2012. Wasted: how America is losing up to 40 percent of its food from farm to fork. NRDC Issue PAPER, iP:12-06-B, https://www.nrdc.org/sites/default/files/wasted-foodIP.pdf (accessed June 2017).

NRDC, 2015. France moves toward a national policy against food waste. NRDC Issue PAPER R-15-08-B, https://www.nrdc.org/sites/default/files/france-food-waste-policy-report.pdf (accessed June 2017).

NRDC, 2017. Wasted: How America is losing up to 40 percent of its food from farm to fork to landfill. NRDC Issue PAPER, R: 17-05-A (2nd edition of NRDC's original paper from 2012). https://www.nrdc.org/sites/default/files/wasted-2017-report.pdf. (accessed August 2017).

Nunes, M.C.N., Emond, J.P., Rautha, M., Deac, S., Chau, K.V., 2009. Environmental conditions encountered during typical consumer retail display affect fruit and vegetable quality and waste. Postharv. Biol. Technol. 51, 232-241.

Okawa, K., 2015. Market and trade impacts of food loss and waste reduction, OECD Food, Agriculture and Fisheries Papers, No. 75, OECD Publishing. http://dx.doi.org/10.1787/5js4w29h0wr2-en (accessed June 2017).

Parfitt, J., Barthel, M., Macnaughton, S., 2010. Food waste within food supply chains: quantification and potential for change to 2050. Phil. Trans. R. Soc. B 365, 3065-3081.

Parizeau, K., von Massow, M., Martin, R., 2015. Household-level dynamics of food waste production and related beliefs, attitudes, and behaviours in Guelph, Ontario. Waste Manag. $35,207-217$.

Poelman, A.A.M., Delahunty, C.M., de Graaf, C., 2017. Vegetables and other core food groups: A comparison of key flavour and texture properties. Food Qual. Pref. 56, 1-7.

Pollard, C.M., Miller, M.R., Daly, A.M., Crouchley, K.E., O’Donoghue, K.J., Lang, A.J., Binns, C.W., 2008. Increasing fruit and vegetable consumption: success of the Western Australian Go for $2 \& 5$ ® campaign. Pub. Health Nutrit. 11, 314-320.

Priefer, C., Jörissen, J., Bräutigam, K.R., 2016. Food waste prevention in Europe - A causedriven approach to identify the most relevant leverage points for action. Resour. Conser. Recyc. 109, 155-165. 
Qi, D., Roe, B.E., 2016. Household food waste: multivariate regression and principal components analyses of awareness and attitudes among U.S. consumers. PLoS One 11, e0159250.

ReFED, 2016. A roadmap to reduce U.S. food waste by $20 \%$. https://www.refed.com/downloads/ReFED_Report_2016.pdf (accessed July 2017).

Richards, T.J., 2000. A Discrete/continuous model of fruit promotion, advertising, and response segmentation. Agribusiness 16, 179-196.

Schulte, E.M., Avena, N.M., Gearhardt, A.N., 2015. Which foods may be addictive? The roles of processing, fat content, and glycemic load. PLoS ONE 10: e0117959. doi:10.1371/journal.pone.0117959

Shen, Y., Kennedy, O.B., Methven, L., 2016. Exploring the effects of genotypical and phenotypical variations in bitter taste sensitivity on perception, liking and intake of brassica vegetables in the UK. Food Qual. Pref. 50, 71-81.

Singh, M., 2014. Mood, food and obesity. Front. Psychol. 5, Article 925, 1-20.

Shafiee-Jood, M., Cai, X., 2016. Reducing food loss and waste to enhance food security and environmental sustainability. Environ. Sci. Technol. 50, 8432-8443.

Stancu, V., Haugaard, P., Lähteenmäki, L., 2016. Determinants of consumer food waste behaviour: Two routes to food waste. Appetite 96, 7-17.

Stefan, V., van Herpen, E., Tudoran, A.A., Lähteenmäki, L., 2013. Avoiding food waste by Romanian consumers: The importance of planning and shopping routines. Food Qual. Pref. $28,375-381$.

Stuart, T., 2009. Waste. Uncovering the Global Food Scandal. Penguin Books, London.

Thompson, A.K., 2010. Controlled Atmosphere Storage of Fruits and Vegetables. CABI, Oxfordshire, UK.

Thyberg, K.L., Tonjes, D.J., 2016. Drivers of food waste and their implications for sustainable policy development. Res. Conserv. Recyc. 106, 110-123.

UNEP, 2014. Prevention and reduction of food and drink waste in businesses and households Guidance for governments, local authorities, businesses and other organisations, Version 1.0. http://www.fao.org/fileadmin/user upload/save-food/PDF/Guidance-content.pdf (accessed June 2017). 
USDA, 2017. Loss-adjusted food availability data. 2017. United States Department of Agriculture. https://www.ers.usda.gov/data-products/food-availability-per-capita-datasystem/ (accessed August 2017).

Valdés, A., Ramos, M., Beltrán, A., Jiménez, A., Garrigós, M.C., 2017. State of the art of antimicrobial edible coatings for food packaging applications. Coatings 7, 56.

Vanderroost, M., Rageart, P., Devlieghere, F., Meulenaer, B.D., 2014. Intelligent food packaging: The next generation. Trends Food Sci. Technol. 39, 47-62.

Verghese, K., Lewis, H., Lockrey, S., Williams, H., 2015. Packaging's role in minimizing food loss and waste across the supply chain. Packag. Technol. Sci. 28, 603-620.

Waitt, G., Phillips, C., 2016. Food waste and domestic refrigeration: a visceral and material approach. Soc. Cultur. Geograp. 17, 359-379.

Wills, R., McGlasson, B., Graham, D., Joyce, D., 1998. Postharvest: An Introduction to the Physiology and Handling of Fruit, Vegetables and Ornamentals, 4th edition, University of New South Wales Press Ltd, Sydney, Australia.

Wheeler, T., Von Braun, J., 2013. Climate change impacts on global food security. Science 341, $508-513$.

White, C., 2016. How to buy fresh fruit online in China.

http://www.fruitnet.com/asiafruit/article/168952/how-to-buy-fresh-fruit-online-in-china (acessed September 2017).

WRAP, 2007. Food behaviour consumer research: quantitative phase.

http://www.wrap.org.uk/sites/files/wrap/Food\%20behaviour\%20consumer\%20research\%20qua ntitative\%20jun\%202007.pdf (accessed July 2017).

WRAP, 2008. Helping consumers reduce fruit and vegetable waste: final report. http:/www.wrap.org.uk/sites/files/wrap/WRAP\%20RTL044-001\%20Final\%20report.pdf (accessed June 2017).

WRAP, 2011. Fruit and vegetable resource maps. Final report by: Terry, L.A., Mena, C., Williams, A., Jenney, N., http://www.wrapcymru.org.uk/sites/files/wrap/Resource_Map_Fruit_and_Veg_final_6_june_2 011.fc479c40.10854.pdf (accessed June 2017). 
WRAP, 2013. Household food and drink waste in the United Kingdom 2012 - final report. http://www.wrap.org.uk/sites/files/wrap/hhfdw-2012-summary.pdf (accessed June 2017). WRI, 2016. Food loss and waste accounting and reporting standard. http://www.wri.org/sites/default/files/REP_FLW_Standard.pdf (accessed June 2017).

Zou, Z., Chen, Q., Uysal, I., Zheng, L., 2014. Radio frequency identification enabled wireless sensing for intelligent food logistics. Phil. Trans. R. Soc. A 372, 20130313. 
Table 1. Summary of resource maps detailing FLW percentages for eleven different F\&V through the supply chain. Redrawn from Terry et al. (WRAP, 2011).

\begin{tabular}{l|lllll}
\hline PRODUCT & FIELD & $\begin{array}{l}\text { GRADING } \\
\text { LOSS }\end{array}$ & $\begin{array}{l}\text { STORAGE } \\
\text { LOSS }\end{array}$ & $\begin{array}{l}\text { PACKING } \\
\text { LOSS }\end{array}$ & $\begin{array}{l}\text { RETAIL } \\
\text { WASTE }\end{array}$ \\
\hline STRAWBERRY & $2-3$ & 1 & 0.5 & $2-3$ & $2-4$ \\
RASPBERRY & 2 & No data & No data & $2-3$ & $2-3$ \\
\hline LETTUCE & $5-10$ & No data & $0.5-2$ & 1 & 2 \\
\hline TOMATO & 5 & 7 & No data & $3-5$ & $2.5-3$ \\
\hline APPLE & $5-25$ & $5-25$ & $3-4$ & $3-8$ & $2-3$ \\
\hline ONION & $3-5$ & $9-20$ & $3-10$ & $2-3$ & $0.5-1$ \\
\hline POTATO & $1-2$ & $3-13$ & $3-5$ & $20-25$ & $1.5-3$ \\
\hline BROCCOLI & 10 & 3 & 0 & 0 & $1.5-3$ \\
\hline AVOCADO & No data & 30 & 5 & 3 & $2.5-5$ \\
\hline CITRUS & No data & 3 & No data & 0.5 & $2-2.5$ \\
\hline BANANA & No data & 3 & No data & $0-3$ & 2 \\
\hline
\end{tabular}

N.B. For presentation purposes the stages in the supply chain are shown sequentially. In practice, harvested produce either will be graded and packed for immediate sale or, where appropriate, stored and then graded and packed. As a result the data for all stored products cannot be used commercially. 


\section{Figure legends}

Fig. 1. FLW percentages at each step along the supply chain in USA, Canada, Australia, and New Zealand. The data are according to FAO (2011) and NRDC (2012).

Fig. 2. The food waste recovery hierarchy established by the United States Environmental Protection Agency (EPA).

Fig. 3. Resource map for potato. Data from Terry et al. (WRAP, 2011).

Fig. 4. Average fresh F\&V shrink rates in U.S. supermarkets during 2011-12. The data are according to Buzby et al. (2016).

Fig. 5. Lengths of time that consumers hold fruit in their homes. Values represent the percentage of homes within which fruit has been held for the specified number of d: (A) grapes = $\bullet$, oranges $=\bullet$, mandarins $=\mathbf{m}$; (B) apples $=\bullet$, banana $=\mathbf{m}$, pear $=\bullet$; (C) nectarine $=\bullet$, green kiwifruit $=\bullet$; (D) lemon $=\bullet$. The number of observations (homes) within which specified fruit were recorded as present was 50 for grapes, 103 for oranges, 114 for mandarins, 253 for apples, 198 for banana, 59 for pear, 27 for nectarine, 85 for green kiwifruit and 104 for lemon. Reanalysis of data (Amos, 2005) collected during an on-line survey of 234 consumers recruited on the basis that they who ate fruit at least once each week; data collection from 1 to 17 August 2005. 
Fig. 6. Retail packages of F\&V.

Fig. 7. A pictogram presenting storage instructions for $\mathrm{F} \& \mathrm{~V}$. The professional recommendations were provided by researchers of the Dept. of Postharvest Storage of Fresh Produce, ARO, the Volcani Center, Israel. 
Fig. 1

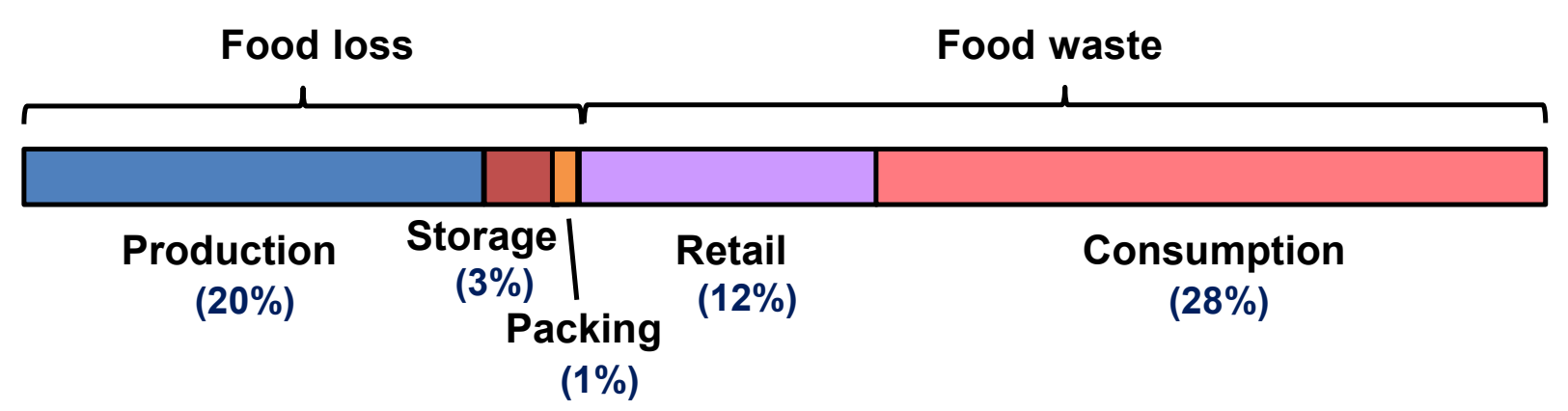

Fig. 1. FLW percentages at each step along the supply chain in the USA, Canada, Australia, and New Zealand combined. The data are according to FAO (2011) and NRDC (2012). 
Fig. 2

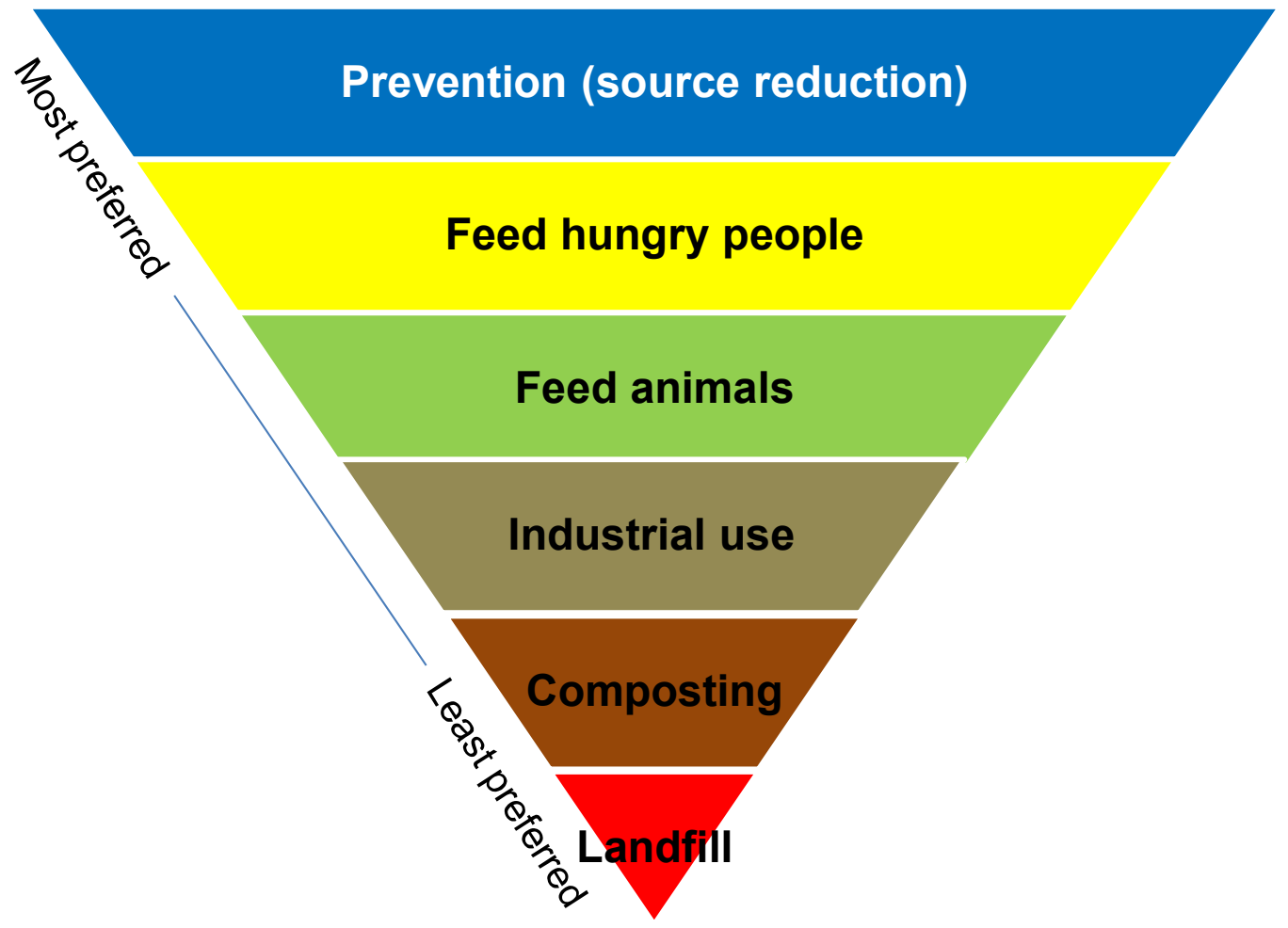

Fig. 2. The food waste recovery hierarchy established by the United States Environmental Protection Agency (EPA). 
Fig. 3

\section{Resource map: Potatoes}

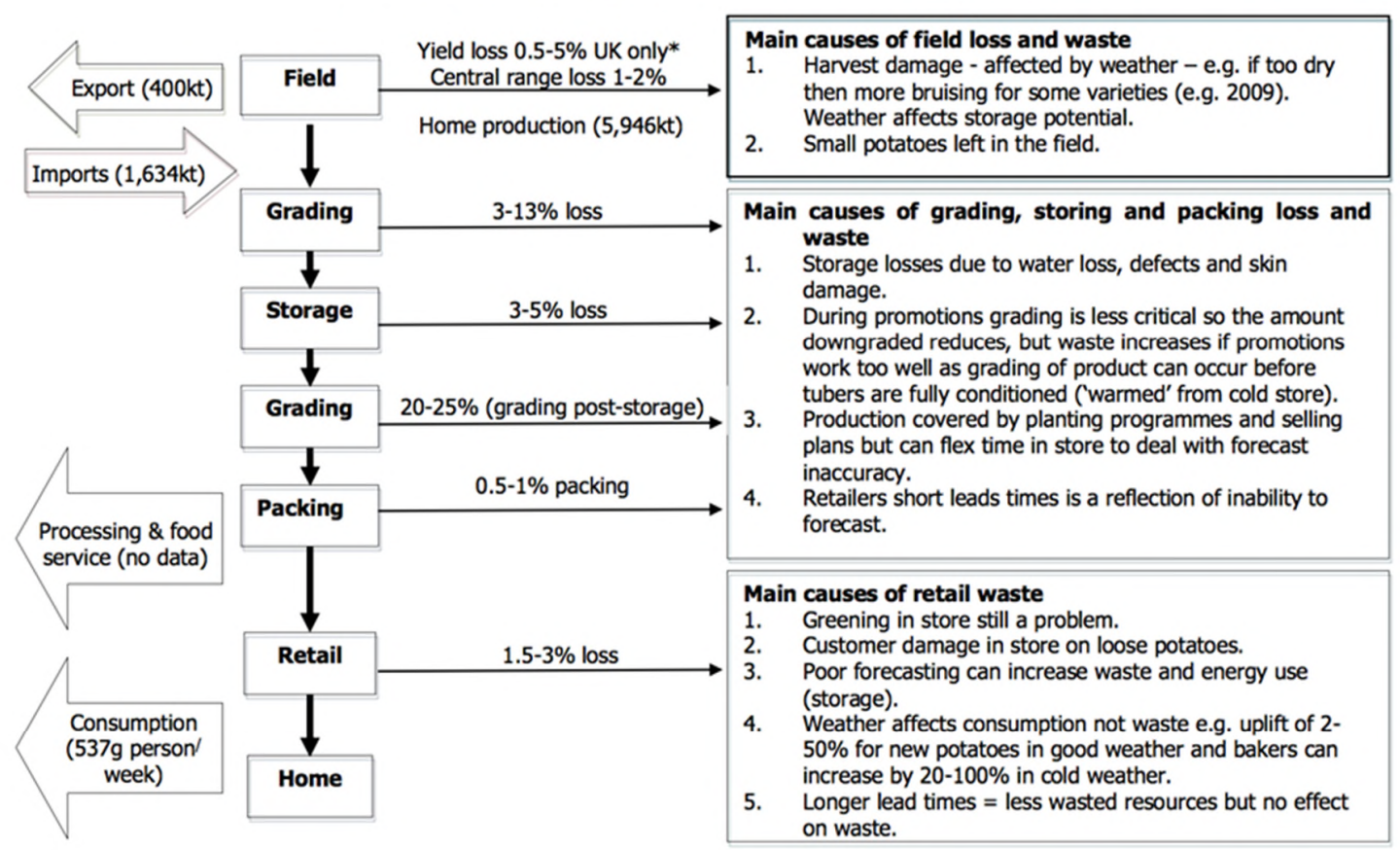

Footnote: $\%$ ranges given in the loss stream were sourced from six principal potato suppliers which make up ca. $60 \%$ market share. $*$ no data on field or other losses associated with imported tubers.
Destination and uses of loss and waste Different market: primary wholesale and processed markets. Animal feed 5-10\% (more in July/August).

Alternate market: composting (field waste - ploughed back and may have beneficial effect on soil condition).

Physical waste: minimal ( $0 \%$ landfill/EfW from suppliers) but prevalent at retailer level.

Fig 3. Resource map for potato. Data from Terry et al. (WRAP, 2011). 
Fig. 4

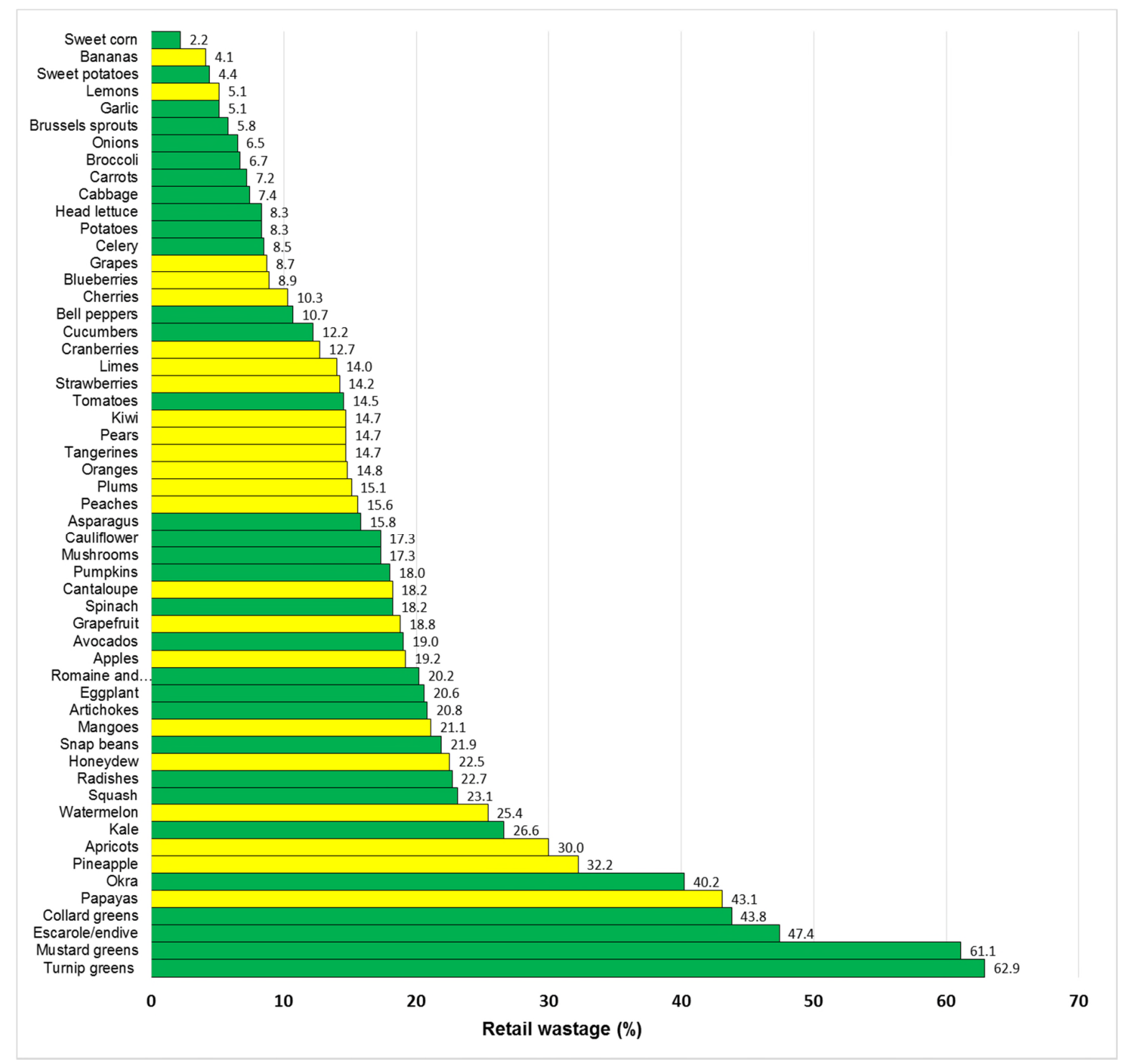

Fig. 4. Average fresh F\&V shrink rates in U.S. supermarkets during 2011-12. The data are according to Buzby et al. (2016). 
Fig. 5

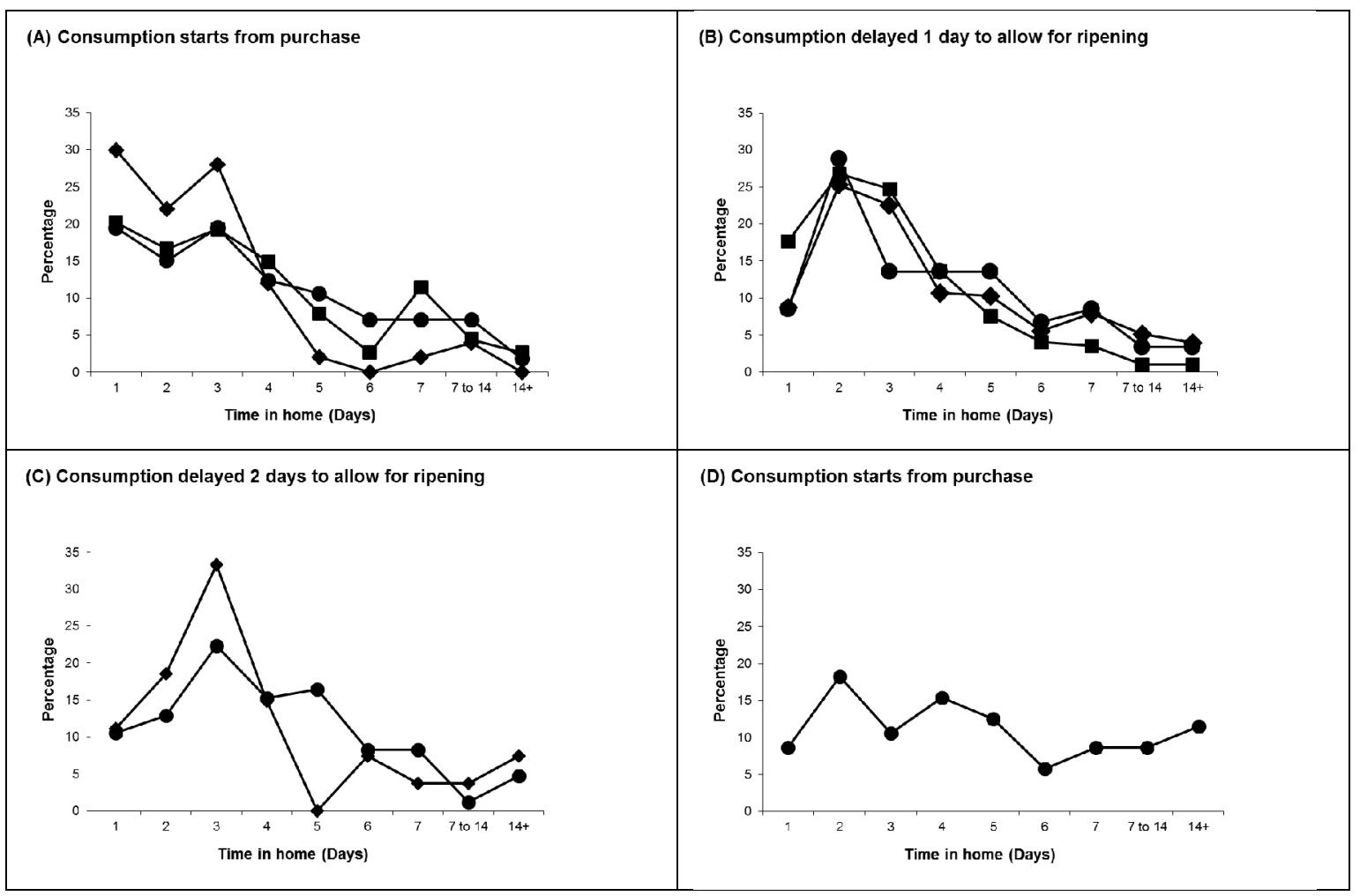

Fig. 5. Lengths of time that consumers hold fruit in their homes. Values represent the percentage of homes within which fruit has been held for the specified number of d: (A) grapes = $\bullet$, oranges $=\bullet$, mandarins $=\mathbf{m}$; (B) apples $=\bullet$, banana $=\mathbf{m}$, pear $=\bullet$; (C) nectarine $=\bullet$, green kiwifruit $=\bullet$; (D) lemon $=\bullet$. The number of observations (homes) within which specified fruit were recorded as present was 50 for grapes, 103 for oranges, 114 for mandarins, 253 for apples, 198 for banana, 59 for pear, 27 for nectarine, 85 for green kiwifruit and 104 for lemon. Reanalysis of data (Amos, 2005) collected during an on-line survey of 234 consumers recruited on the basis that they who ate fruit at least once each week; data collection from 1 to 17 August 2005. 
Fig. 6
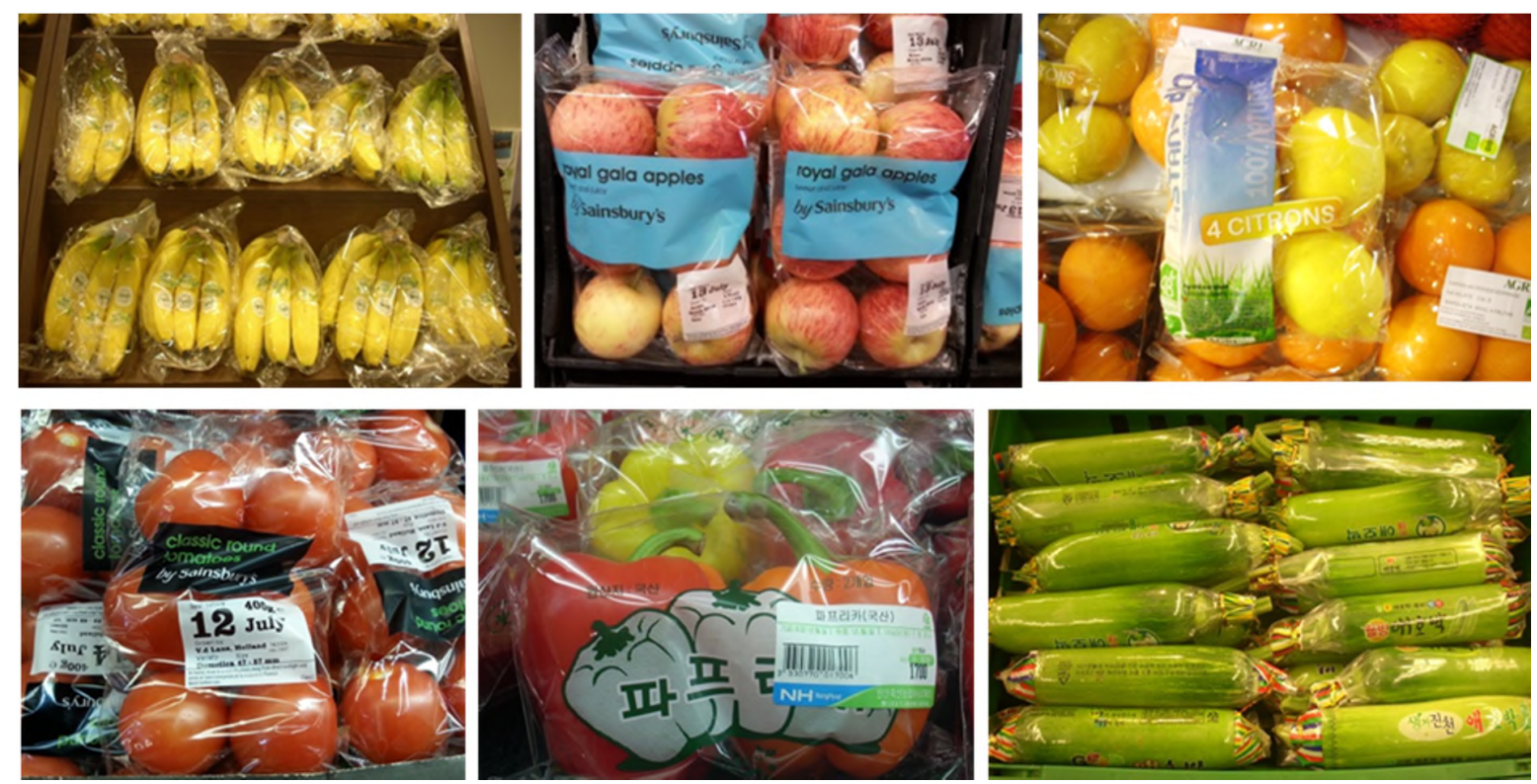

Fig. 6. Retail packages of $F \& V$. 
Fig. 7

\section{How to store fruit $\&$ vegetables in consumer's homes?}

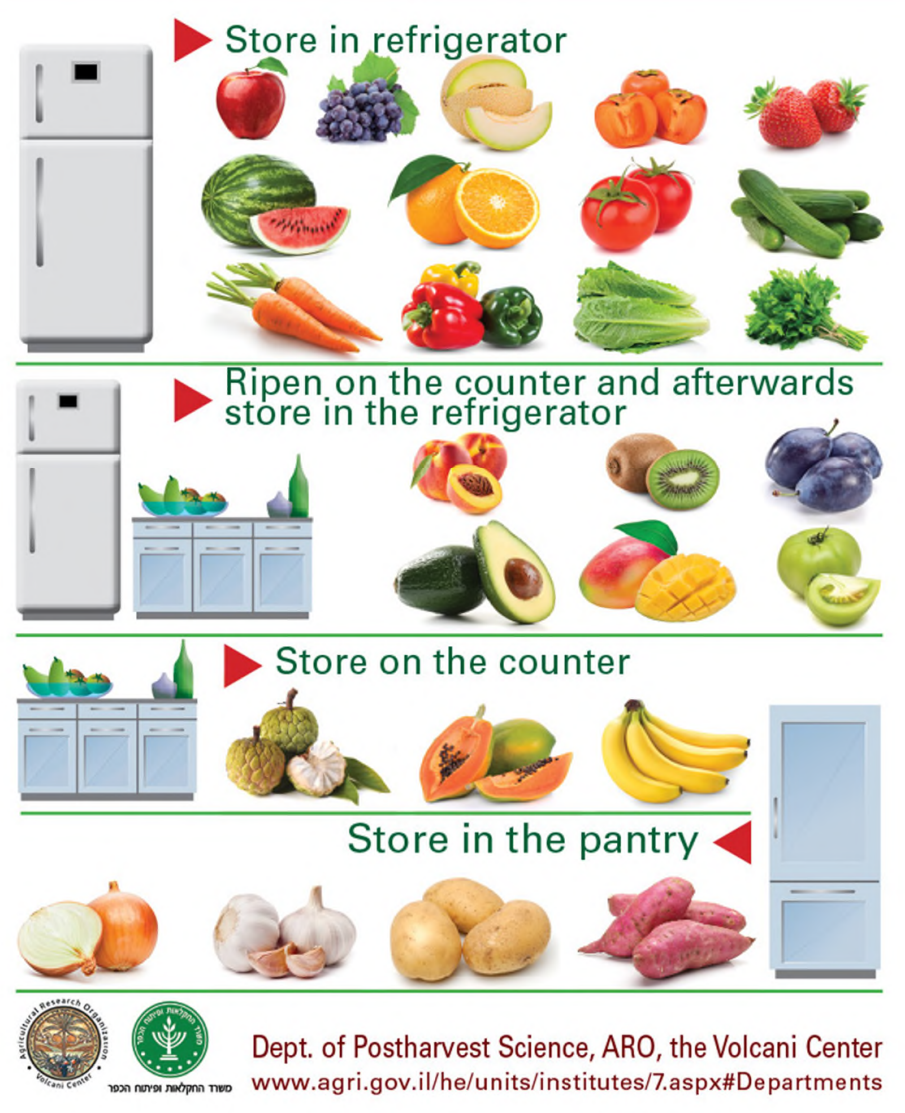

Fig. 7. A pictogram presenting storage instructions for $F \& V$. The professional recommendations were provided by researchers of the Dept. of Postharvest Storage of Fresh Produce, ARO, the Volcani Center, Israel. 